A) Check for updates

Cite this: Food Funct., 2021, 12, 2644

\section{Effects of a Myrciaria jaboticaba peel extract on starch and triglyceride absorption and the role of cyanidin-3-O-glucoside}

\author{
Pamela Alves Castilho, ${ }^{a}$ Lívia Bracht, ${ }^{\mathrm{b}}$ Lillian Barros, (D) ${ }^{\mathrm{c}}$ Bianca R. Albuquerque, (D) \\ Maria Inês Dias, (D) c Isabel C. F. R. Ferreira, (iD c Jurandir Fernando Comar, ${ }^{\text {c }}$ \\ Tamires Barlati Vieira da Silva, ${ }^{a}$ Rosane Marina Peralta, ${ }^{b}$ \\ Anacharis Babeto de Sá-Nakanishib and Adelar Bracht (iD *b
}

\begin{abstract}
The purpose of this study was to perform a parallel and comparative investigation of the effects of a Myrciaria jaboticaba (common name jabuticaba) peel extract and of its constituent cyanidin-3-O-glucoside on the overall process of starch and triglyceride intestinal absorption. The peel extract inhibited both the porcine pancreactic $\alpha$-amylase and the pancreatic lipase but was 13.6 times more potent on the latter (IC 50 values of 1963 and $143.9 \mu \mathrm{gL}^{-1}$, respectively). Cyanidin-3-O-glucoside did not contribute significantly to these inhibitions. The jabuticaba peel extract inhibited starch absorption in mice at doses that were compatible with its inhibitory action on the $\alpha$-amylase. No inhibition of starch absorption was found with cyanidin-3-O-glucoside doses compatible with its content in the extract. The extract also inhibited triglyceride absorption, but at doses that were considerably smaller than those predicted by its strength in inhibiting the pancreatic lipase $\left(\mathrm{ID}_{50}=3.65 \mathrm{mg} \mathrm{kg}{ }^{-1}\right)$. In this case, cyanidin-3-O-glucoside was also strongly inhibitory, with $72 \%$ inhibition at the dose of $2 \mathrm{mg} \mathrm{kg}^{-1}$. When oleate + glycerol were given to mice, both the peel extract and cyanidin-3-O-glucoside strongly inhibited the appearance of triglycerides in the plasma. The main mechanism seems, thus, not to be the lipase inhibition but rather the inhibition of one or more steps (e.g., transport) in the events that lead to the transformation of free fatty acids in the intestinal tract into triglycerides. Due to the low active doses, the jabuticaba peel extract presents many favourable perspectives as an inhibitor of fat absorption and cyanidin-3-O-glucoside seems to play a decisive role.
\end{abstract}

Received 6th November 2020, Accepted 22nd February 2021 DOI: $10.1039 /$ dOfo02927k

rsc.li/food-function

\section{Introduction}

Myrciaria jaboticaba, belonging to the Myrtaceae family, is a fructiferous plant from Brazil, extensively cultivated mainly in the southeastern part of the country. The fruits, known as jabuticaba, are globular with a thick skin and juicy pulp, and are generally sweet. ${ }^{1}$ They present a high content in phenolics, anthocyanins, ellagic acid, and a pronounced antioxidant capacity in vitro. ${ }^{2}$ Jabuticaba possesses a high commercial potential thanks to its pleasant sensorial properties in addition to its nutritional and functional properties. ${ }^{3}$ Its popularity has been compared to that of the berries in North

${ }^{a}$ Post-Graduate Program in Food Sciences, State University of Maringa, 87020-900 Maringá, Paraná, Brazil

${ }^{b}$ Department of Biochemistry, State University of Maringa, 87020-900 Maringá,

Paraná,Brazil.E-mail: adebracht@uol.com.br,abracht@uem.br

${ }^{c}$ Centro de Investigação de Montanha (CIMO), Instituto Politécnico de Bragança,

Campus de Santa Apolónia, 5300-253 Bragança, Portugal
America. Due to its sweet and characteristic taste the pulp of jabuticaba has been consumed either in natura or used in the production of jams, wines, liqueurs and juices. The jabuticaba skin, on the other hand, is rigid and has an astringent taste. It is usually discarded as residue by the food industry, but it is also a potential source of bioactive molecules and a functional food. $^{2,4}$ In a recent study, several phenolic compounds have been identified in a hydroalcoholic extract of the skins among anthocyanins (e.g., cyanidin-3-O-glucoside) and nonanthocyanins. ${ }^{5}$

There are several reports attributing metabolic effects to extracts or chemical components of both the jabuticaba whole fruit and skin. For example, the daily intake during 40 days of 1 to $2 \mathrm{~g} \mathrm{~kg}^{-1}$ of a dried hydroalcoholic extract of the whole fruit by diabetic rats caused substantial diminution in the levels of total cholesterol and triacylglycerols in the plasma and a reduction in post-prandial glycemia. ${ }^{6}$ These effects were attributed, partly at least, to the inhibition of the pancreatic lipase by the extract. The $\mathrm{IC}_{50}$ of the total fruit extract for this 
inhibition, however, was very high, namely $1080 \mu \mathrm{g} \mathrm{mL}^{-1}$ of the reaction medium, a point to be taken into account in terms of future clinical applications. ${ }^{6}$ In line with an effect on lipid metabolism is the report of experiments in which the dried jabuticaba peel was fed to rats and which resulted in increased excretion of fecal triglycerides. ${ }^{7}$ In another study in which obese rodents were fed with diets containing fractions of dried skin, increased HDL cholesterol and diminished insulin levels were found. ${ }^{8}$ Cyanidin-3-O-glucoside, the main anthocyanin of the skin, ${ }^{5}$ has also been frequently associated with lipid metabolism. Food supplementation with cyanidin-3$O$-glucoside to obese mice reduced body weight, visceral adiposity, hepatic steatosis and plasma levels of triacylglycerols. $^{9-11}$ It also reduced hyperglycemia and improved sensitivity to insulin in diabetic mice. ${ }^{12}$ Many of these effects have been attributed to the ability of cyanidin-3$O$-glucoside in modulating the activity of the lipoprotein lipase in tissues and in increasing the activity of the brown adipose tissue. ${ }^{9,10}$

The observations that were summarized above strongly indicate that jabuticaba extracts and its constituent cyanidin-3-Oglucoside affect lipid and possibly also carbohydrate metabolism. The most striking possibility is an action on triglyceride and possibly also on starch absorption from the intestinal tract. Close examination of the reports, however, reveal that a direct proof that these events really occur in vivo is still lacking. Furthermore, mechanistic details of the action of jabuticaba extracts and of their main constituent cyanidin-3-Oglucoside are still to be elucidated. For this reason, we decided to investigate in detail these actions in mice by administering defined doses of an hydroalcoholic extract of jabuticaba peel and cyanidin-3-O-glucoside and by measuring their actions on triglyceride and starch absorption. An hydroalcoholic peel extract was used instead of a total fruit extract for two main reasons. The first reason is that most studies on the biological effects of the jabuticaba have been conducted using peel extracts. The second one is that cyanidin-3-O-glucoside, a compound that is of particular interest for the present study, seems to be fairly abundant in the skin. ${ }^{5}$ If this commercially available compound participates in a significant way in the effects of jabuticaba extracts, the study may open the way for detailed and refined mechanistic studies using cellular systems.

\section{Materials and methods}

\section{Materials}

Porcine pancreatic $\alpha$-amylase (type IV-B), pancreatic lipase (type II) and potato starch were purchased from Sigma-Aldrich. Cyanidin-3-O-glucoside hydrochloride (C3G, 98\% pure) was purchased from Biopurify Phytochemicals Ltd (Chengdu, China). Phenolic compound standards (ellagic acid, quercetin3-O-glucoside and cyanidin-3-O-glucoside) were purchased from Extrasynthese (Genay, France). Excipient-free acarbose and orlistat were obtained from Manipulação Farmácias São
Paulo (Maringá, Brazil). Origin of both products is Fagron SM (Waregem, Belgium). All reagent grade chemicals were from the highest possible degree of purity.

\section{Preparation of hydroethanolic extract of $M$. jaboticaba peels}

The jabuticaba skins (peels) were purchased from the Belo Farm (São Paulo State, Brazil). They were dried in a recirculation oven at $45{ }^{\circ} \mathrm{C}$ and ground to a fine powder. This powder was suspended in a $70 \%$ hydroalcoholic solution at a proportion of $10 \mathrm{~g}$ powder per $100 \mathrm{~mL}$ extraction solution. The mixture was kept on a rotary shaker $(120 \mathrm{rpm})$ for 2 hours at room temperature and protected from light. Agitation was followed by filtration through Whatman 1 and the filtrate was collected. The solid residue was submitted to two additional and successive extractions. The combined filtrates were concentrated in an oven at $45{ }^{\circ} \mathrm{C}$ for ethanol evaporation. The aqueous solution was finally lyophilized and stored in freezer at $-20{ }^{\circ} \mathrm{C}$.

\section{Determination of the phenolic profile of the hydroethanolic extract of the M. jaboticaba peels}

For determining the phenolic profile of the sample, the lyophilized extract $(10 \mathrm{mg})$ was re-dissolved in $2 \mathrm{~mL}$ of ethanol : water $(70: 30 \mathrm{v} / \mathrm{v})$ and filtered through a $0.22 \mu \mathrm{m}$ disposable filter disk into an amber vial for HPLC analysis.

Non-anthocyanin and anthocyanin compounds were determined by high-performance liquid chromatography (Dionex Ultimate 3000 UPLC, Thermo Scientific, San Jose, CA, USA), with diode-array detector $(280,330$, and $370 \mathrm{~nm}$ wavelengths for non-anthocyanin compounds, and $520 \mathrm{~nm}$ wavelength for anthocyanin compounds) linked to an electrospray ionization mass spectrometer working in negative mode (non-anthocyanin compounds) and positive mode (anthocyanin compounds) (Linear Ion Trap LTQ XL, Thermo Scientific, San Jose, CA, USA) under conditions previously described. ${ }^{13}$ Phenolic compounds were identified comparing their UV-vis and MS retention times with those obtained from available standards and data from our compound library and the literature. The results were expressed in $\mathrm{mg} \mathrm{g}^{-1}$ extract.

\section{Animals}

The present work was approved by the Ethics Committee on the Use of Animals in Experimentation (CEUA) of the State University of Maringá (protocol number 9577260819). Male Swiss mice weighing between 35 and $40 \mathrm{~g}$ were used (age of approximately 40 days). The mice were fed with standard chow diet and received water ad libitum. Three animals were kept in each cage according to the universally accepted guidelines for animal experimentation.

\section{Pancreatic $\alpha$-amylase assay and kinetics}

The activity of the porcine pancreatic $\alpha$-amylase (initial reaction rate) was measured as the rate of reducing sugar formation. ${ }^{14}$ The reaction medium was $20 \mathrm{mM}$ phosphate buffer, $\mathrm{pH}$ 6.9, containing $6.7 \mathrm{mM} \mathrm{NaCl}{ }^{15,16}$ Substrate (starch), enzyme and inhibitors (jabuticaba peel extract or cyanidin-3-O-glucoside hydrochloride) were all dissolved into this medium. The volume 
of the final reaction medium was equal to $1.0 \mathrm{~mL}$ and was composed of $500 \mu \mathrm{L}$ substrate solution, $250 \mu \mathrm{L}$ inhibitor solution and $250 \mu \mathrm{L}$ enzyme solution. The final concentrations of starch were in the range between 0.05 and $1 \mathrm{~g}$ per $100 \mathrm{~mL}$, those of the $M$. jaboticaba peel extract in the range between 20 and $4000 \mu \mathrm{g}$ $\mathrm{mL}^{-1}$ and those of cyanidin-3-O-glucoside in the range between 5 and $160 \mu \mathrm{g} \mathrm{mL} \mathrm{m}^{-1}$. The enzyme concentration in all incubations was equal to 0.75 units per $\mathrm{mL}$ under the conditions of the assay. Initially reaction medium and the substrate solution were mixed and incubated for 5 minutes at $37{ }^{\circ} \mathrm{C}$. This was followed by the addition of the enzyme solution. After 10 minutes incubation at $37{ }^{\circ} \mathrm{C}$ the reaction was stopped by keeping the reaction tube in boiling water for 5 minutes. The reducing sugars were determined by the 3,5-dinitrosalicylate method, using maltose as standard. ${ }^{14}$ Absorbance, which is directly proportional to the concentration of reducing sugars, was read at $540 \mathrm{~nm}$. Interference by the components of the extract or cyanidin-3-O-glucoside with the absorbance measurements was monitored by parallel incubations containing the same inhibitor concentrations and buffer solution in place of the enzyme. To these incubations samples 3,5-dinitrosalicylate was added and their absorbance subtracted from the absorbance of the incubations containing the enzyme. The reaction rates were expressed as $\mu \mathrm{mol}$ per minute.

\section{Pancreatic lipase assay and kinetics}

The activity of the pancreatic lipase (initial reaction rate) was measured using $p$-nitrophenyl-palmitate as substrate. ${ }^{17}$ The latter was suspended in isopropanol and the suspension was sonicated until complete solubilization. The enzyme (porcine pancreatic lipase) was initially suspended in Tris- $\mathrm{HCl}$ buffer at the concentration of $2 \mathrm{mg} \mathrm{mL^{-1 }}$. This suspension was centrifuged $(2000 \mathrm{~g}, 5 \mathrm{~min}$ ) and the supernatant used as the enzyme source. The reaction medium was $10 \mathrm{mM}$ Tris- $\mathrm{HCl}$ buffer $(\mathrm{pH}$ 8.2) containing $p$-nitrophenyl-palmitate at various concentrations in the range up to $530 \mu \mathrm{M}$, according to the experimental protocol. The $M$. jabuticaba peel extract was added for final concentrations of up to $300 \mu \mathrm{g} \mathrm{mL} \mathrm{m}^{-1}$, according to the experimental protocol. Cyanidin-3-O-glucoside was added for final concentrations of up to $200 \mathrm{mg} \mathrm{mL}^{-1}$. The incubation temperature was $37^{\circ} \mathrm{C}$. After 5 minutes the reaction was started by adding an aliquot of the enzyme solution $(0.1 \mathrm{~mL})$. The reaction was stopped after 10 minutes by keeping the reaction tube in boiling water for 5 minutes. After cooling at room temperature, the reaction tube was centrifuged $(21000 \mathrm{~g}$ for $10 \mathrm{~min}$ ) and the absorbance of the supernatant, due to the released $p$-nitrophenol, was determined at $410 \mathrm{~nm}$ against a blank containing the denatured enzyme. Interference by the components of the extract or cyanidin-3-O-glucoside with the absorbance measurements was monitored by parallel incubations containing the same inhibitor concentrations and buffer solution in place of the enzyme. The absorbance of these samples was subtracted from the absorbance of the incubations containing the enzyme. The reaction rate was expressed as $\mu \mathrm{mol}$ per minute using the extinction coefficient of $1.83 \times 10^{4} \mathrm{M}^{-1} \mathrm{~cm}^{-1}$.

\section{Starch tolerance test in mice}

Fasted mice (18 hours) were used and the administration route was in all cases intragastric (by gavage). The number of animals for each experimental approach was between 5 and 7 . Positive controls received commercial corn starch $(1 \mathrm{~g}$ per $\mathrm{kg}$ body weight) and negative controls filtered tap water. ${ }^{16}$ The M. jaboticaba extract was administered at the doses of 250 or $500 \mathrm{mg} \mathrm{kg}^{-1}$ to two different groups of mice in addition to commercial corn starch. Cyanidin-3-O-glucoside was given at the doses of $10 \mathrm{mg} \mathrm{kg}^{-1}$ or $20 \mathrm{mg} \mathrm{kg}^{-1}$ to two different groups of mice in addition to commercial corn starch. Finally, experiments were also done with the reference substance acarbose which was given to the mice at the dose of $50 \mathrm{mg} \mathrm{kg}^{-1}$ in addition to commercial corn starch. Plasma glucose was determined at times 0, 30, 60, 90 and 120 minutes after starch administration. Blood samples were collected from the tail vein and analyzed by means of a glucometer (AccuChek®).

\section{Glucose tolerance test in mice}

Glucose tolerance was assayed in order to find out if the $M$. jaboticaba extract interferes with glucose transport across the enterocytes (intestinal cells). Fasted mice were used after a fasting period of $18 \mathrm{~h}$. Two different doses of $M$. jaboticaba extract were administered to different groups of animals, $250 \mathrm{mg} \mathrm{kg}^{-1}$ and $500 \mathrm{mg} \mathrm{kg}^{-1}$. Controls received just filtered tap water. Glucose was administered intragastrically to all animals $\left(1.5 \mathrm{~g} \mathrm{~kg}^{-1}\right)$. Blood samples were collected from the tail vein at times 0, 30, 60, 90 e 120 minutes and analyzed by means of a glucometer (AccuChek®).

\section{Triglyceride tolerance test in mice}

Intestinal triglyceride absorption was evaluated by means of the tolerance to olive oil after 18 hours fasting. ${ }^{17}$ The M. jaboticaba extract was solubilized in filtered water and the following doses were administered intragastrically to different groups of animals: 1, 5, 25 and $250 \mathrm{mg}$ per $\mathrm{kg}$ of body weight; the controls received filtered water in place of the extract solution. Cyanidin-3-O-glucoside was equally solubilized in filtered tap water and given intragastrically to two different groups of animals at the doses of 0.2 and $2 \mathrm{mg}$ per $\mathrm{kg}$ body weight; here again the controls received filtered water in place of the cyanidin-3-O-glucoside solution. The reference substance orlistat was given to a separate group of animals at the dose of $50 \mathrm{mg}$ $\mathrm{kg}^{-1}$. After drug administration all animals received intragastrically olive oil ( $5 \mathrm{~mL}$ per $\mathrm{kg}$ body weight). The plasma triglyceride levels were determined at 0, 1.5, 3.0, 4.5 and 6.0 hours in blood samples collected from the tail vein. For each experimental procedure 3 to 4 animals were used.

Measurement of blood triglycerides was carried out by means of an AccutrendPlus ${ }^{\circledR}$ Roche triglyceride meter. The choice of this method was based on the advantage that only drops of blood are needed. Such small samples can be easily obtained from the tail vein of the mice. The method of assay of the AccutrendPlus ${ }^{\circledR}$ Roche triglyceride meter is an endpoint enzymatic-colorimetric assay, which actually measures 
the glycerol moiety of the triglycerides. As such it suffers a small interference by free glycerol, which is generally accepted as tolerable for clinical purposes. ${ }^{18}$ It was shown that the AccutrendPlus® Roche triglyceride meter measures with almost equal precision both VLDL and chylomicron triglycerides. Comparison with a conventional enzymatic method revealed a mean difference of $0.94 \%$ between both methods. ${ }^{18}$

\section{Triglycerides in plasma after oleate administration to mice}

The animals were deprived of food for 18 hours prior to the experiments. Solutions $(100 \mu \mathrm{L})$ of the $M$. jaboticaba peel extract and cyanidin-3-O-glucoside were administered orally at the doses of 5 and $25 \mathrm{mg} \mathrm{kg}^{-1}$ and 0.2 and $2 \mathrm{mg} \mathrm{kg}^{-1}$, respectively. Controls received tap water $(200 \mu \mathrm{L})$. Oleic acid $(180 \mu \mathrm{L})$ plus glycerol $(20 \mu \mathrm{L})$ were administered orally to all animals. Additional controls were done by administering separately glycerol $(20 \mu \mathrm{L})$ or oleic acid $(180 \mu \mathrm{L})$. Blood samples from the tail vein were analyzed with the AccutrendPlus ${ }^{\circledR}$ Roche triglyceride meter as described in the preceding item at zero time (just before glycerol and oleate administration) and after 90 minutes.

\section{Calculations and statistical criteria}

Numerical interpolation for the determination of the halfmaximal inhibitor concentrations $\left(\mathrm{EC}_{50}\right)$ was done using the Scientist software from MicroMath Scientific Software (Salt Lake City, UT). The same program was used for fitting the rate equations to the experimental initial rates of enzymatic activity by means of an iterative non-linear least-squares procedure. The decision about the most adequate model (equation) was based on the model selection criterion (MSC) and on the standard deviations of the optimized parameters. The model selection criterion, which corresponds to the normalized Akaike Information Criterion, is defined as: ${ }^{19}$

$$
\mathrm{MSC}=\ln \left[\frac{\sum_{i=1}^{n} w_{i}\left(Y_{\mathrm{obs}_{i}}-\bar{Y}_{\mathrm{obs}}\right)^{2}}{\sum_{i=1}^{n} w_{i}\left(Y_{\mathrm{obs}_{i}}-Y_{\mathrm{cal}_{i}}\right)^{2}}\right]-\frac{2 p}{n}
$$

$Y_{\text {obs }}$ are the experimental reaction rates, $\bar{Y}_{\text {obs }}$ the mean experimental reaction rate, $Y_{\text {cal }}$ the theoretically calculated reaction rate, $\mathrm{w}$ the weight of each experimental point, $n$ the number of observations and $p$ the number of parameters of the set of equations. In the present work, the model with the largest MSC value was considered the most appropriate, provided that the estimated parameters were positive. When the MSC values differed by less than $5 \%$, the mode yielding the smallest standard deviations for the estimated parameters was considered the most appropriate one.

\section{Results}

\section{Phenolic profile of the hydroethanolic extract of $M$. jaboticaba peels}

Previous to the biological assays, the phenolic profile of the M. jaboticaba peel extract was determined. Table 1 presents chromatographic parameters, spectral data and contents. Phenolic compounds were identified according to the chromatographic characteristics, ultraviolet light absorption and mass spectra, as previously described in the literature for jabuticaba residues. ${ }^{5,13}$ The phenolic profile of the jabuticaba peels extract used in the present work includes twelve compounds, ten nonanthocyanin compounds and two anthocyanins. Among nonanthocyanin compounds, ellagic acid derivatives (peaks 1-9) were most abundant, and a quercetin derivative, namely quercitrin (peak 10), was also found. The anthocyanin compounds detected were a delphinidin-3-O-glucoside and a cyanidin-3-Oglucoside (peaks 11 and 12, respectively), the latter being the most representative, as already described in the literature. ${ }^{5,13}$

\section{Effects of the jabuticaba peel extract and cyanidin-3-O- glucoside on $\alpha$-amylase}

The possible action of the jabuticaba peel extract on the pancreatic $\alpha$-amylase was investigated based on reports that similar preparations may influence blood glucose levels. Inhibition of the pancreatic $\alpha$-amylase is a possible mechanism. The results of the first experiments are shown in Fig. 1. The extract in fact inhibited the pancreatic $\alpha$-amylase with a well-defined concentration dependence. Inhibition, however, occurred at relatively high concentrations. This is reflected by the $\mathrm{IC}_{50}$ value, which numerical interpolation revealed to be equal to $1963 \mu \mathrm{g} \mathrm{mL} \mathrm{m}^{-1}$. When the reciprocal reaction rates $(1 / v)$ were plotted against the extract concentrations, the relationship turned out to be parabolic, an observation that predicts the presence of quadratic (or higher order) inhibitor concentration terms in the steady-state rate equation (parabolic inhibition).

The next question that can be formulated is one about the possible contribution of cyanidin-3-O-glucoside to the inhibitory effects of the jabuticaba peel extract on the $\alpha$-amylase activity. The experiments that were done in order to find an answer to this question are shown in Fig. 2. Concentrations of up to $330 \mu \mathrm{M}$ cyanidin-3-O-glucoside were investigated $(160 \mu \mathrm{g}$ $\mathrm{mL}^{-1}$ ). This highest concentration caused $13.3 \%$ inhibition. For the extract concentration that caused 50\% inhibition, $1963 \mu \mathrm{g} \mathrm{mL} \mathrm{m}^{-1}$, the fraction corresponding to cyanidin-3-O-glucoside was equal to $24.2 \mu \mathrm{g} \mathrm{mL}^{-1}(50 \mu \mathrm{M})$ according to Table 1 . The total concentration of the non-anthocyanidin polyphenolics for this extract concentration, on the other hand, was equal to $55.9 \mu \mathrm{g} \mathrm{mL}^{-1}(59.9 \mu \mathrm{M})$.

Fig. 3 shows the results that were obtained when starch (substrate) and extract (inhibitor) concentrations were varied simultaneously. The usual saturation curve in the absence of inhibitor was progressively lowered when the extract concentration was raised. The curves present no tendency of converging at high substrate concentrations, excluding, thus, competitive inhibition. In the search for the most adequate model that would be able to describe the curves in Fig. 3, the best fit was obtained with eqn (2):

$$
v=\frac{V_{\max }[\mathrm{S}]}{K_{\mathrm{M}}\left(1+\frac{[\mathrm{I}]}{K_{\mathrm{i} 1}}+\frac{[\mathrm{I}]^{2}}{K_{\mathrm{i} 1} K^{\prime}{ }_{\mathrm{i} 1}}\right)+[\mathrm{S}]\left(1+\frac{[\mathrm{I}]}{K_{\mathrm{i} 2}}\right)}
$$


Table 1 Phenolic profile of the hydroethanolic extract of $M$. jaboticaba peel

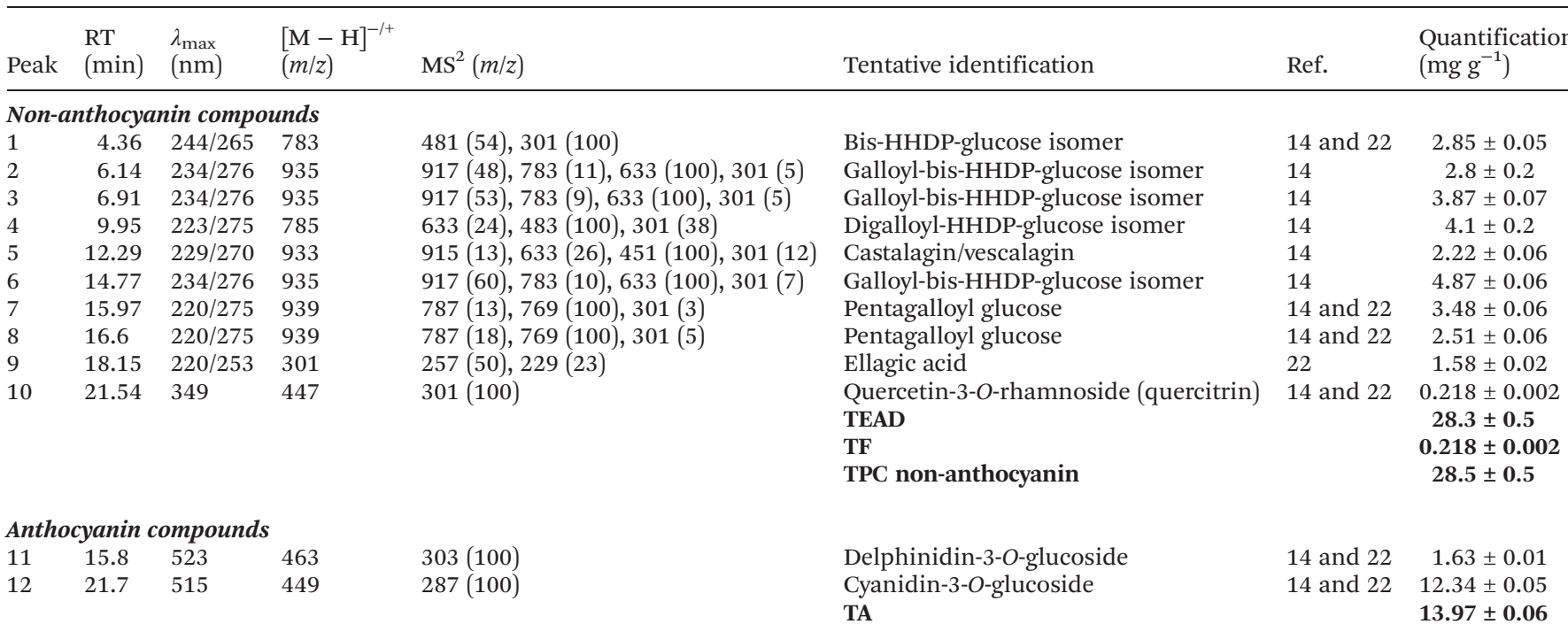

RT: retention time; TEAD: total ellagic acid derivatives; TF: total flavonols; TPC: total phenolic compounds; TA: total anthocyanins; HDDP: hexahydroxydiphenoyl. Phenolic compounds used for quantification: ellagic acid $\left(y=26719 x-317255\right.$. $\left.R^{2}=0.9989\right)$; quercetin-3-O-glucoside $(y=$ $\left.34843 x-160173 . R^{2}=0.9998\right)$; and cyanidin-3-O-glucoside $\left(y=97787 x-743469 . R^{2}=0.9993\right)$.

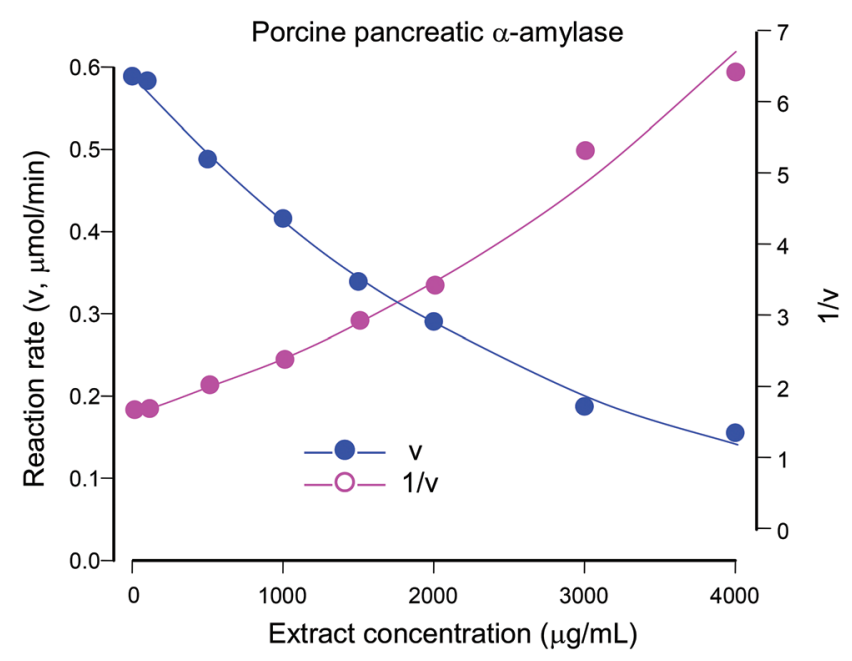

Fig. 1 Concentration dependences of the inhibition caused by the Myrciaria jaboticaba peel extract on the porcine $\alpha$-amylase. Each datum point is the mean of four determinations. Standard errors of the mean cannot be seen when smaller than the symbols. Reaction rates $(v)$ and reciprocals of the reaction rates $(1 / v)$ were represented versus the inhibitor concentrations.

This equation describes a mechanism in which inhibition is brought about by the formation of EI, $\mathrm{EI}_{2}$ and ESI complexes, $K_{\mathrm{i} 1}, K_{\mathrm{i} 1}$ and $K_{\mathrm{i} 2}$ being the corresponding dissociation constants. ${ }^{15,16}$ The $E_{\mathrm{I} 2}$ complex is responsible for the parabolic nature of the inhibition, as revealed by the non-linear relationship between $1 / v$ and $[\mathrm{I}]$. The continuous lines in Fig. 3 were calculated with the optimized parameters obtained in the fitting procedure. It should be noted that eqn (2) was fitted simultaneously to the whole data set, allowing the obtainment of the whole set of parameters.

\section{Effects of the extract and cyanidin-3-O-glucoside on the pancreatic lipase}

Inhibition of the pancreatic lipase by a whole jabuticaba fruit extract was previously observed. ${ }^{6}$ The experiments in this work were done in order to confirm this effect for the peel extract and also for evaluating its strength and possible mechanistic details. The concentration dependence of the inhibition is shown in Fig. 4. The extract clearly inhibited the enzyme in a concentration-dependent manner; 50\% inhibition, evaluated by numerical interpolation, can be expected at the extract concentration of $143.9 \mu \mathrm{g} \mathrm{mL} \mathrm{m}^{-1}$. The skin extract is, thus, 7.5 times more potent than the total fruit extract, whose $\mathrm{IC}_{50}$ value was reported to be $1080 \mu \mathrm{g} \mathrm{mL}{ }^{-1} .^{6}$ It is also a much more potent inhibitor of the pancreatic lipase than of the pancreatic $\alpha$-amylase, actually 13.6-fold stronger. Plotting of the inverse of the reaction rates $(1 / v)$ against the concentrations (Fig. 4) resulted in a parabola, denoting multiple binding of the inhibitor or inhibitors to the enzyme.

Similarly to what was done with the $\alpha$-amylase, the effects of cyanidin-3-O-glucoside on the pancreatic lipase were also measured. The results are shown in Fig. 5. The concentration of cyanidin-3-O-glucoside was varied in the range of up to $200 \mu \mathrm{g} \mathrm{mL}{ }^{-1}$, which in molar terms corresponds to a concentration of $412.5 \mu \mathrm{M}$. The compound can be considered a weak inhibitor of the pancreatic lipase. Even at the highest concentration, $412.5 \mu \mathrm{M}$, inhibition reached only $25 \%$. Cyanidin-3-O-glucoside in the extract is clearly not the main responsible for the inhibitory effect of the preparation. The 


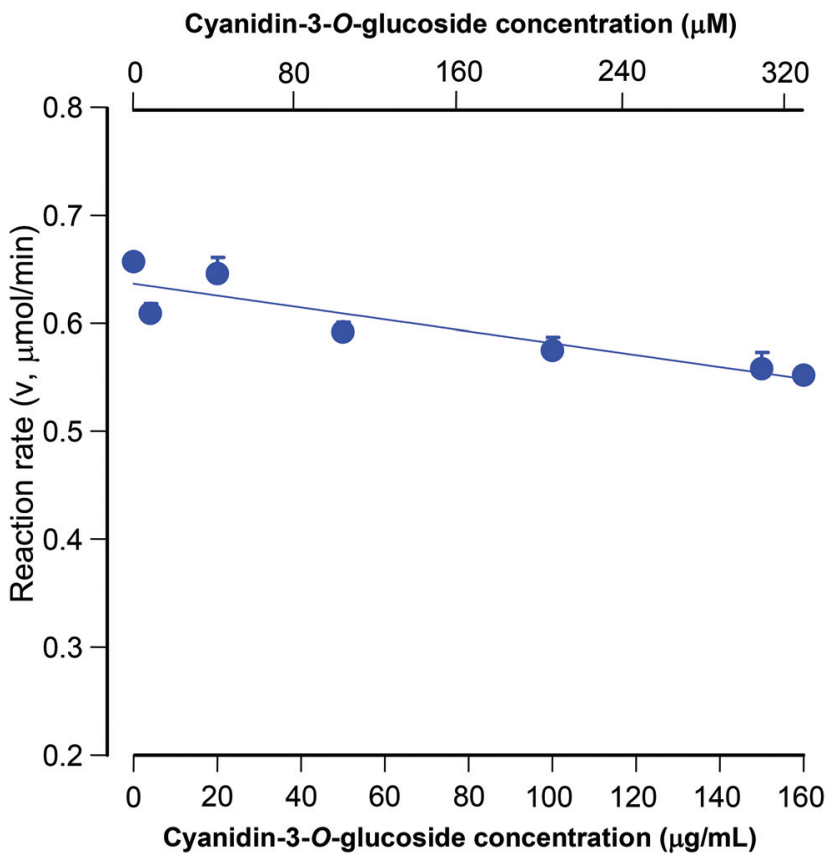

Fig. 2 Concentration dependence of the inhibition caused by cyanidin3 -O-glucoside on the porcine pancreatic $\alpha$-amylase. Each datum point is the mean of three determinations. Standard errors of the mean cannot be seen when smaller than the symbols. The continuous line was calculated from the relation $y=0.634-0.000262 x(r=0.92 ; x$ corresponds to the $\mu \mathrm{M}$ concentration), obtained by fitting the equation describing the straight line to the data by means of a least squares procedure.

extract concentration that caused $50 \%$ inhibition at a concentration of $143.9 \mu \mathrm{g} \mathrm{mL} \mathrm{mL}^{-1}$ contains $1.77 \mu \mathrm{g} \mathrm{mL} \mathrm{m}^{-1}$ cyanidin3-O-glucoside and $4.1 \mu \mathrm{g} \mathrm{mL}^{-1}$ total non-anthocyanin polyphenolics.

The effects of the jabuticaba peel extract on the substrate saturation curves of the porcine pancreatic lipase are shown in Fig. 6. Similar experiments were not done with cyanidin3-O-glucoside because this compound, by being a weak inhibitor, would need concentrations far above its solubility limits. As shown in a previous work, the enzyme shows a substrate-inhibition phenomenon at high $p$-nitrophenyl palmitate concentrations. ${ }^{17}$ The position of the curves obtained in the presence of the jabuticaba skin extract are consistent with the inhibition already demonstrated in Fig. 4. They do not present any tendency of converging with the control curve, suggesting a priori that the inhibition is not of the competitive type. Attempts at fitting a steady-state equation to the whole data set took into account this fact and also the previous observation that inhibition is probably of the parabolic type. The best fit was obtained with the following equation:

$$
v=\frac{V_{\max }[\mathrm{S}]}{K_{\mathrm{M}}\left(1+\frac{[\mathrm{I}]}{K_{\mathrm{i} 1}}\right)+[\mathrm{S}]\left(1+\frac{[I]^{2}}{\left(\bar{K}_{\mathrm{i} 2}\right)^{2}}\right)\left(1+\frac{[\mathrm{S}]}{K_{\mathrm{iS}}}\right)}
$$

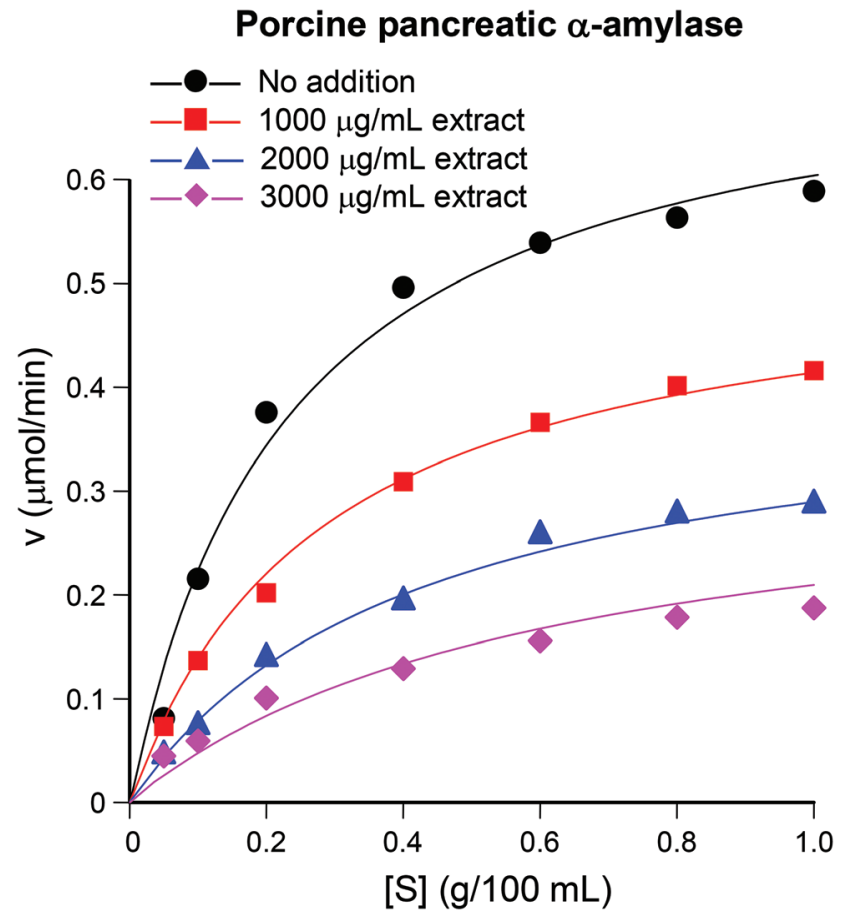

Fig. 3 Reaction rates of the porcine pancreatic $\alpha$-amylase obtained by varying simultaneously the concentrations of the substrate ([S]; starch) and the Myrciaria jaboticaba peel extract. Each datum point is the mean of four determinations. The lines running through the experimental points were calculated using optimized parameters obtained by fitting eqn (2) to the experimental data by means of a nonlinear least-squares procedure. Values of the optimized parameters and goodness of fit indicators are: $K_{M}, 0.233 \pm 0.025 \mathrm{~g}$ per $100 \mathrm{~mL} ; V_{\max }, 0.745 \pm 0.027 \mu \mathrm{mol}$ $\min ^{-1} ; K_{\mathrm{i} 1}, 4109.4 \pm 3854.7 \mu \mathrm{g} \mathrm{mL}^{-1} ; K_{\mathrm{i} 1}^{\prime} 543.9 \pm 0.594 \mu \mathrm{g} \mathrm{mL}{ }^{-1} ; K_{\mathrm{i} 2}$, $2470.1 \pm 441.0 \mu \mathrm{g} \mathrm{mL}^{-1}$; sum of squared deviations, 0.00744 ; MSC, 4.237; correlation, 0.994 .

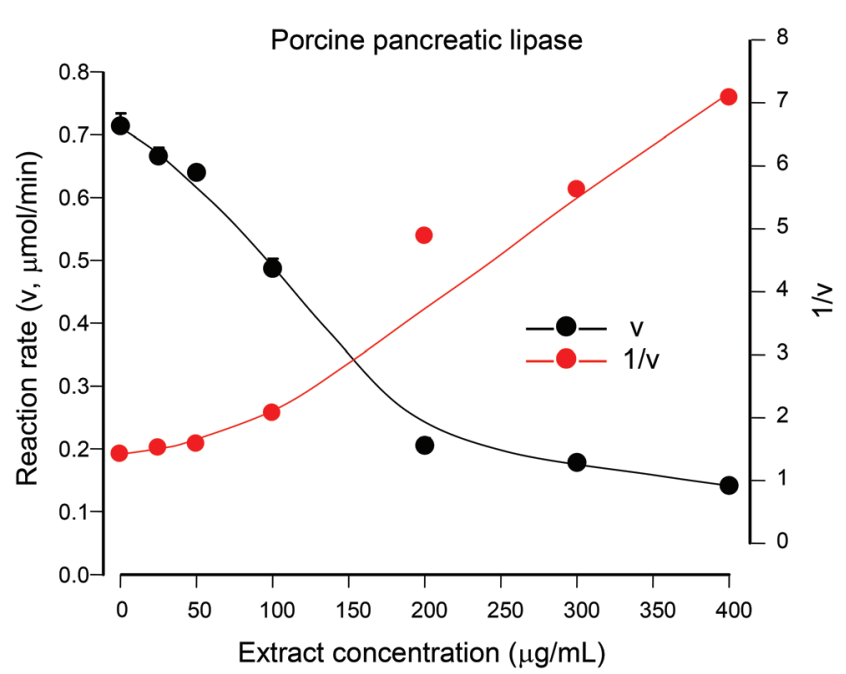

Fig. 4 Concentration dependences of the inhibition caused by the Myrciaria jaboticaba peel extract on the porcine pancreatic lipase. Each datum point is the mean of four determinations. Standard errors of the mean cannot be seen when smaller than the symbols. Reaction rates $(v)$ and reciprocals of the reaction rates $(1 / v)$ were represented versus the inhibitor concentrations. 


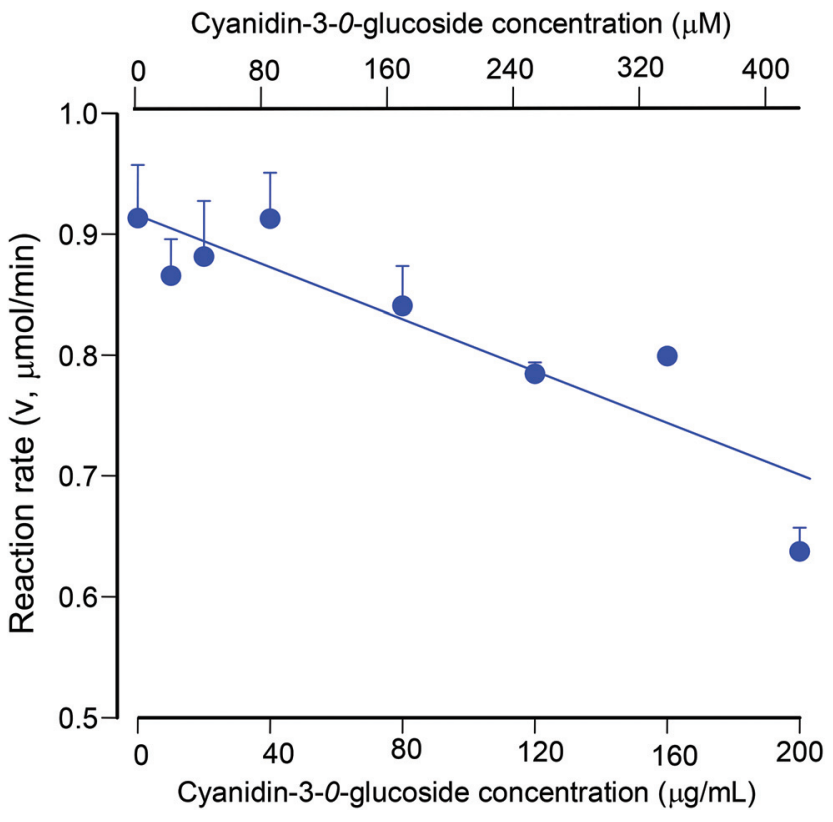

Fig. 5 Concentration dependence of the inhibition caused by cyanidin3-O-glucoside on the porcine pancreatic lipase. Each datum point is the mean of three determinations. Standard errors of the mean cannot be seen when smaller than the symbols. The continuous line was calculated from the relation $y=0.916-0.000531 x(r=0.91 ; x$ corresponds to the $\mu \mathrm{M}$ concentration), obtained by fitting the equation describing the straight line to the data by means of a least squares procedure.

Eqn (3) represents a mechanism of mixed inhibition by the jabuticaba skin extract with formation of the complexes EI and $\mathrm{ESI}_{2} . V_{\max }$ and $K_{\mathrm{M}}$ represent the maximal reaction rate and the Michaelis-Menten constant, respectively. ${ }^{17} K_{\text {is }}$ is the substrate inhibition constant and $K_{\mathrm{i} 1}$ and $\bar{K}_{\mathrm{i} 2}$ are the inhibition constants. Fitting was unsuccessful when a quadratic term of [I] was omitted. The continuous lines running through the experimental points in Fig. 6 were calculated using eqn (3) with the optimized parameters obtained in the least-squares fitting procedure. Values of the optimized parameters are listed in the legend to Fig. 6. The inhibition constant $K_{\mathrm{i} 1}$ refers to the dissociation of the EI complex. Its value $\left(33.3 \mu \mathrm{g} \mathrm{mL}{ }^{-1}\right)$ is much smaller than that of the dissociation constant of the $\mathrm{ESI}_{2}$, complex, which is $\bar{K}_{\mathrm{i} 2}\left(171.3 \mu \mathrm{g} \mathrm{mL} \mathrm{mL}^{-1}\right)$. This means that, at low concentrations, inhibition is mainly caused by binding to the free enzyme.

\section{Effects on starch absorption}

Inhibition of starch absorption by jabuticaba formulations has equally been suggested and can actually be expected based on the inhibitory effects on the $\alpha$-amylase shown in Fig. 1. Our approach to this question is shown in Fig. 7. After starch administration to mice $\left(1 \mathrm{~g} \mathrm{~kg}^{-1}\right)$, blood glucose concentrations were monitored for up to 120 minutes. The control curve showed the usual rise in blood glucose with maximal values between 40 and 60 minutes. ${ }^{15}$ Low doses in the range of up to $25 \mathrm{mg} \mathrm{kg}{ }^{-1}$ did not affect starch absorp-

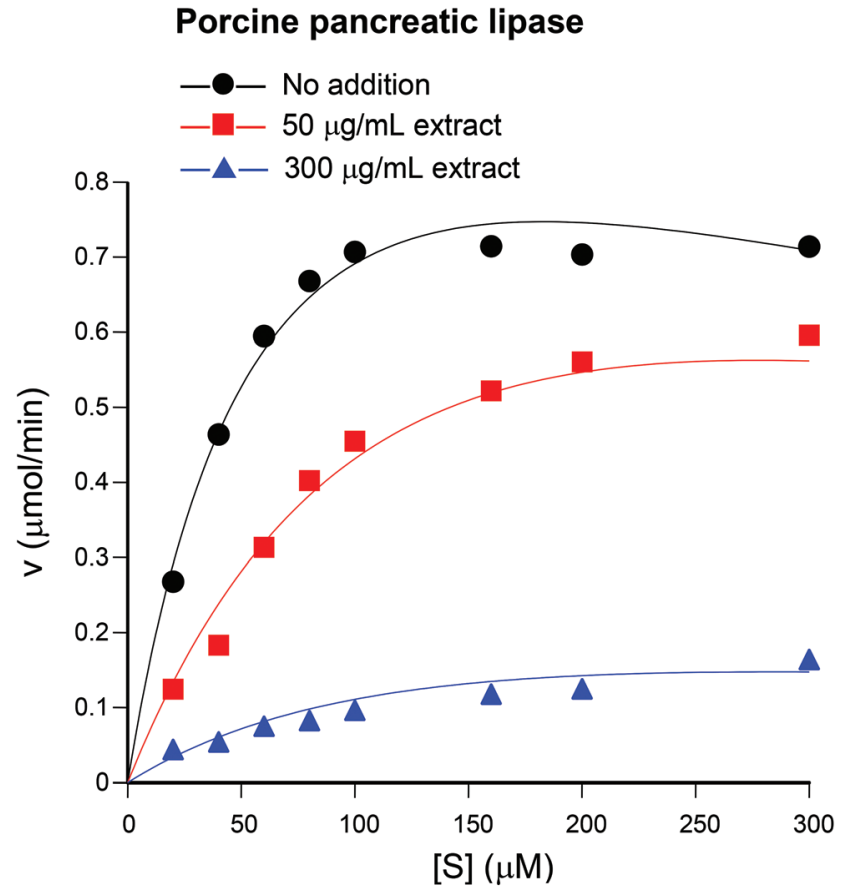

Fig. 6 Reaction rates of the porcine pancreatic lipase obtained by varying simultaneously the concentrations of the substrate ([S]; $p$-nitrophenyl palmitate) and of the Myrciaria jaboticaba peel extract. Each datum point is the mean of four determinations. The lines running through the experimental points were calculated using optimized parameters obtained by fitting eqn (3) to the experimental data by means of a nonlinear least-squares procedure. Values of the optimized parameters and goodness of fit indicators are: $K_{\mathrm{M}}, 69.4 \pm 14.7 \mu \mathrm{M} ; V_{\max }, 1.31$ $\pm 0.16 \mu \mathrm{mol} \min ^{-1} ; K_{\mathrm{i} 1}, 33.3 \pm 4.0 \mu \mathrm{g} \mathrm{mL}^{-1} ; \bar{K}_{\mathrm{i} 2}, 171 . \overline{3} \pm 76.7 \mu \mathrm{g} \mathrm{mL}^{-1} ; K_{\mathrm{is}}$ $=481.9 \pm 159.5 \mu \mathrm{M}$; sum of squared deviations, $0.01132 ; \mathrm{MSC}, 4.702$; correlation, 0.997

tion (not shown). When much higher doses were administered, however, a clear inhibitory effect was found, as shown in Fig. 7(A). The $500 \mathrm{mg} \mathrm{kg}{ }^{-1}$ dose attenuated the concentration versus time curve in a way that is not very far from the attenuation caused by $50 \mathrm{mg} \mathrm{kg}^{-1}$ acarbose, the classical inhibitor of starch absorption. Fig. 7(B) allows to compare the areas under the curves subtracted from the area under the curve when water was given in place of starch. The jabuticaba peel extract doses of 250 and $500 \mathrm{mg} \mathrm{kg}^{-1}$ reduced the area under the curves by 51 and $84 \%$, respectively. These extract doses contained 3.2 and $6.1 \mathrm{mg} \mathrm{kg}^{-1}$ cyanidin-3-O-glucoside, respectively, and 7.12 and $14.25 \mathrm{mg} \mathrm{kg}^{-1}$ total nonanthocyanin polyphenolics.

Even though cyanidin-3-O-glucoside is a weak inhibitor of the $\alpha$-amylase, effects on other hydrolytic enzymes ( $\alpha$-glucosidase) and steps of the intestinal glucose absorption process cannot be excluded. This justifies the experiments shown in Fig. 8, in which starch was given to mice in addition to 10 and $20 \mathrm{mg} \mathrm{kg}{ }^{-1}$ cyanidin-3-O-glucoside. These two doses of pure cyanidin-3-O-glucoside are higher than those contained in the 250 and $500 \mathrm{mg} \mathrm{kg}^{-1}$ peel extract doses of the experiment shown in Fig. 7. Hence, if the com- 

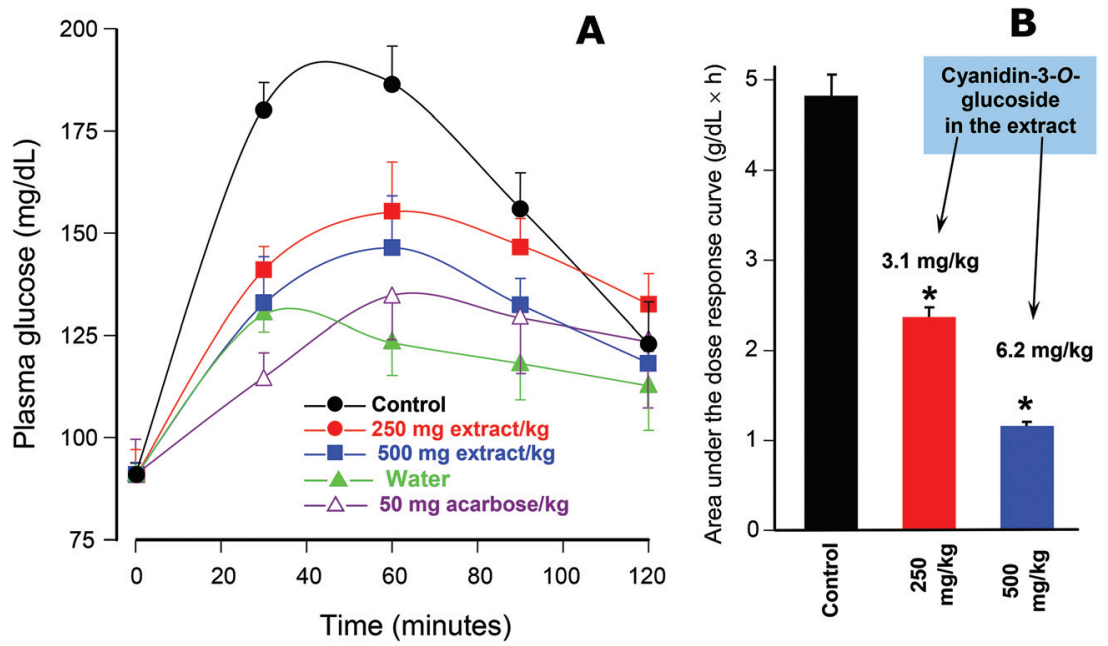

Fig. 7 (A) Blood glucose concentration profiles after intragastric starch loads in mice: the effect of the M. jaboticaba residues extract. The oral administration of commercial starch ( $1 \mathrm{~g}$ per $\mathrm{kg}$ body weight) was done immediately after the administration of the extracts or acarbose. The doses and their estimated contents in cyanidin-3-O-glucoside are given on the graphs. Plasma glucose was measured as described in Materials and methods. Each value represents the mean \pm mean standard error of 4 mice. (B) Areas under the curves obtained after the various treatments with of $M$. jaboticaba extract illustrated by panel (A) subtracted from the area under the curve obtained after water administration. Asterisks indicate statistical significance relative to the control curve $(p \leq 0.05)$.

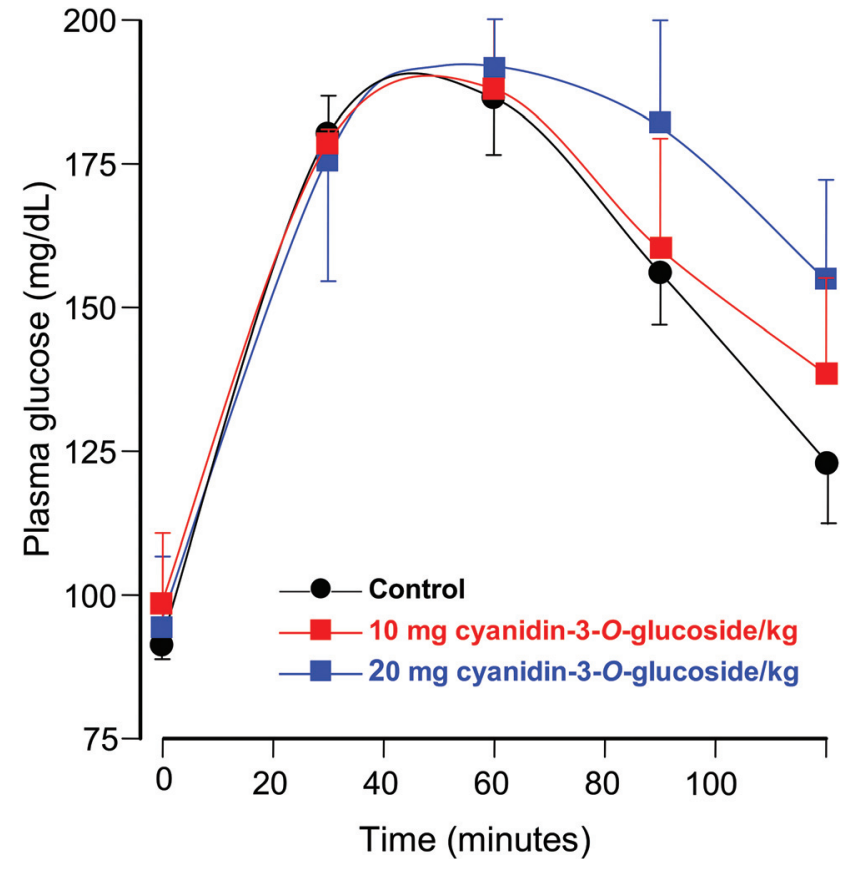

Fig. 8 Blood glucose concentration profiles after intragastric starch loads in mice: the effect of cyanidin-3-O-glucoside administration. The oral administration of commercial starch ( $1 \mathrm{~g}$ per $\mathrm{kg}$ body weight) was done immediately after the administration of cyanidin-3-O-glucoside. The doses are given on the graph. Plasma glucose was measured as described in Materials and methods. Each value represents the mean \pm mean standard error of 3 mice.

pound gives a significant contribution to the effects of the extract, this should be detectable. Apparently, cyanidin-3-Oglucoside, at the doses that were given, does not inhibit starch absorption, an observation that is consistent with its weak inhibitory activity on $\alpha$-amylase. Actually, there is even a tendency toward higher glycemic levels after 90 minutes, especially with the $20 \mathrm{mg} \mathrm{kg}^{-1}$ dose. Statistical significance is lacking, however.

Starch hydrolysis is essential but not the phenomenon that immediately precedes glucose entry into the systemic circulation. The released glucose reaches the circulation after transport across the cell membranes of the cells lining the intestinal lumen. The glucose tolerance experiments shown in Fig. 9 were done as an additional control in order to find out if the jabuticaba peel extract is able to inhibit absorption of free glucose. The results revealed that at least the 250 and $500 \mathrm{mg} \mathrm{kg}^{-1}$ doses did not modify the response of the mice after an intragastric glucose load. Inhibition of glucose transport across the enterocyte is, thus, unlikely.

\section{Effects on triglyceride absorption}

The question if the jabuticaba peel extract interferes with triglyceride absorption was approached by administering olive oil to mice and by subsequently following the plasma concentration of triglycerides. It is well established that the absorption of triglycerides in the intestine depends on the activity of the pancreatic lipase, which splits these molecules into products that are de facto absorbed and which are in a subsequent stage used to restore the triglycerides that appear in the plasma. ${ }^{20}$ Fig. $10(\mathrm{~A})$ illustrates the time course of the changes in plasma triglycerides concentrations following the administration of olive oil $\left(5 \mathrm{~mL} \mathrm{~kg}^{-1}\right)$ under various conditions. The sole administration of olive oil (control curve) was followed by a clear rise in the plasma concentration of triglycerides with a 


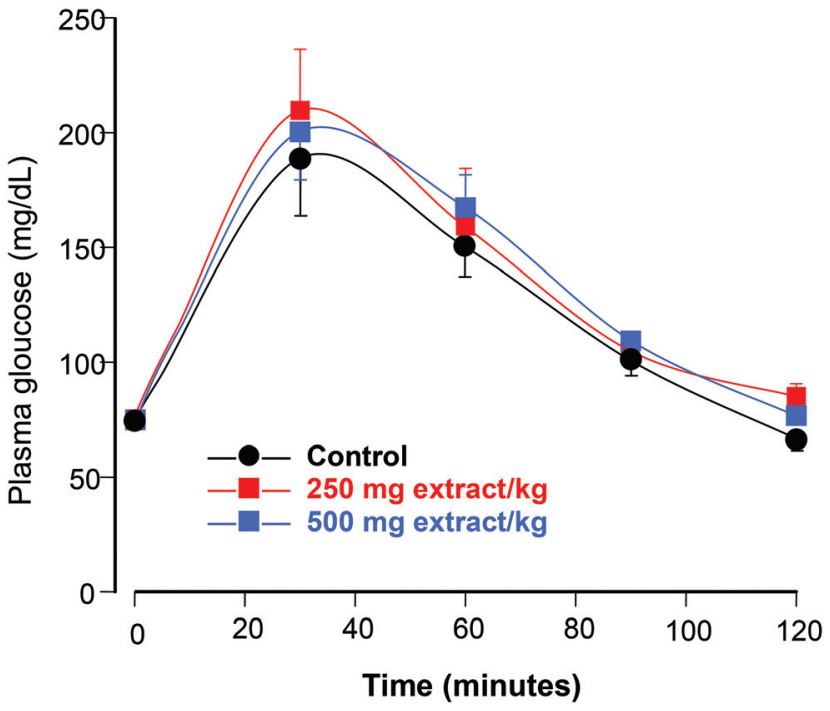

Fig. 9 Blood glucose concentration profiles after intragastric glucose loads in mice: the effect of the M. jaboticaba peel extract. The oral administration of glucose ( $1.5 \mathrm{~g}$ per $\mathrm{kg}$ body weight) was done immediately after the administration of the extract. The doses are given on the graph. Plasma glucose was measured as described in Materials and methods. Each value represents the mean \pm mean standard error of 4 mice.

peak after 3 hours. After this peak the triglyceride concentration declined slowly. After six hours it was close, but still above, the concentration found at the administration time (zero time). The experiments were repeated with mice to which various doses of the jabuticaba peel extract or orlistat had been administered. As expected, orlistat almost totally prevented the rise in the plasma triglyceride concentration. The various doses of the jabuticaba peel extract modified the response in a concentration dependent manner. The lowest dose $\left(1 \mathrm{mg} \mathrm{kg}^{-1}\right)$ accelerated the initial rise, but it also accelerated the decline to values under those of the control curve at 4.5 hours. Extract doses from 5 to $250 \mathrm{mg} \mathrm{kg}^{-1}$ shifted the response curve progressively in the direction of the curve obtained with orlistat.

Fig. 10(B) shows the areas under the triglyceride curves subtracted from the area under the curve obtained when orlistat was given. This procedure normalizes the responses. Administration of the jabuticaba peel extract produced a dosedependent decrease in the normalized area under the timeresponse curves, suggesting inhibition of triglyceride absorption as the predominant effect. This is true even for the lowest dose, which showed an initial increment above the control curve. With the dose of $5 \mathrm{mg} \mathrm{kg}^{-1}$ the diminution of the normalized area was equal to $67 \%$. Numerical interpolation revealed that $50 \%$ diminution can be expected at the dose of $3.65 \mathrm{mg} \mathrm{kg}^{-1}$.

Fig. 10(B) informs also, in addition to the peel extract doses, the approximated doses of cyanidin-3-O-glucoside that were automatically administered with the extract, calculated using the content given in Table 1 . Based solely on the data
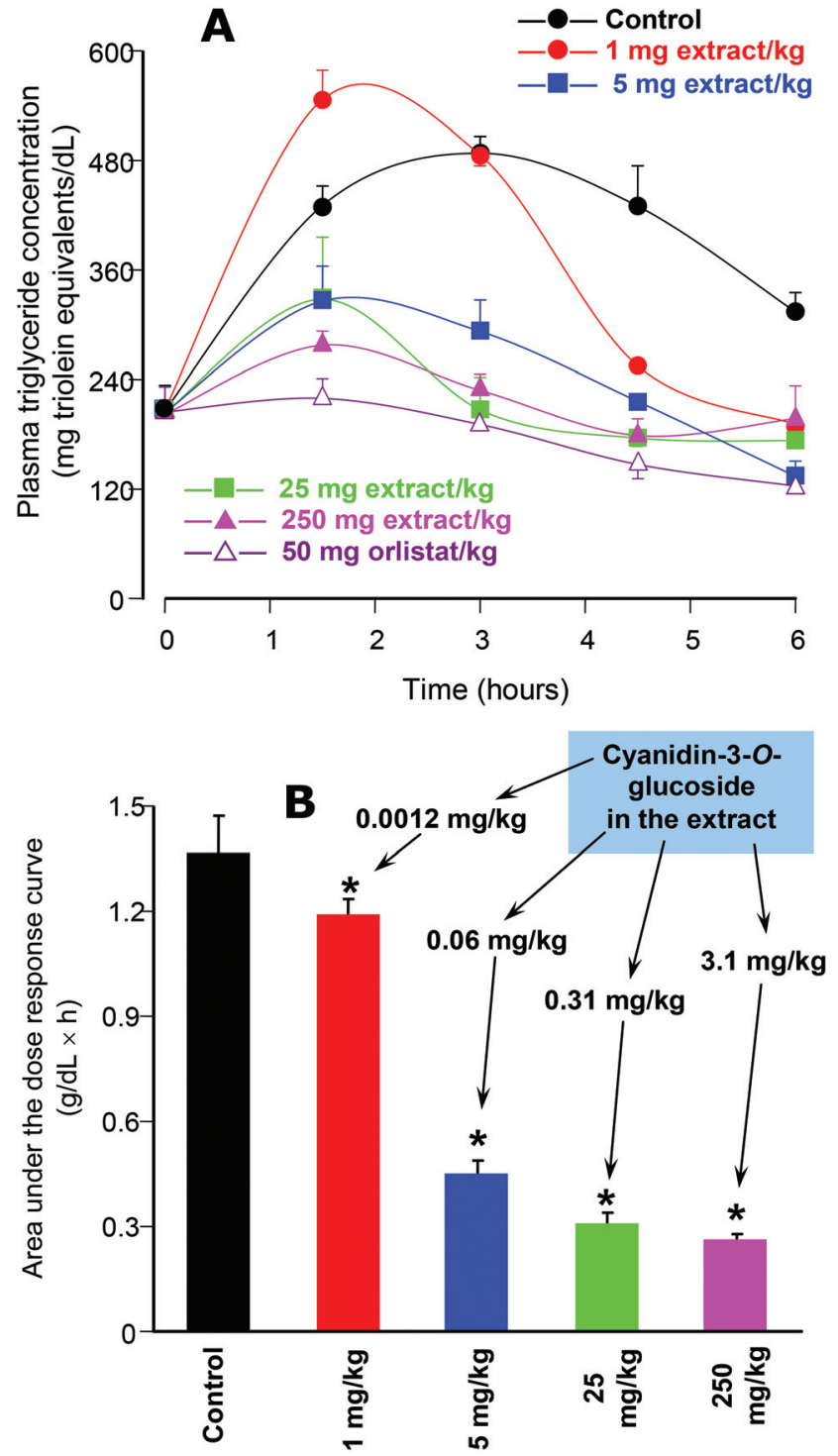

Fig. 10 (A) Blood triglyceride concentration profiles after intragastric olive oil loads in mice: the effect of the $M$. jaboticaba residues extract. The oral administration of olive oil $\left(5 \mathrm{~mL} \mathrm{~kg}^{-1}\right)$ was done immediately after the administration of the extracts or orlistat. The doses and their estimated contents in cyanidin-3-O-glucoside are given on the graphs. Plasma triglycerides were measured as described in Materials and methods. Each value represents the mean \pm mean standard error of 4 mice. (B) Areas under the curves obtained after the various treatments with of $M$. jaboticaba extract illustrated by panel (A) subtracted from the area under the curve obtained after orlistat administration. Asterisks indicate statistical significance relative to the control curve $(p \leq 0.05)$.

obtained when the pancreatic lipase was measured, pure cyanidin-3-O-glucoside doses in the range depicted in Fig. 10(B) should not affect triglyceride absorption. Fig. 11 shows, however, that this prediction was not confirmed. Two doses of cyanidin-3-O-glucoside were administered, 0.2 and $2 \mathrm{mg} \mathrm{kg}{ }^{-1}$. The lower dose caused an initial increment in the concentration of triglycerides after olive oil administration to mice, 

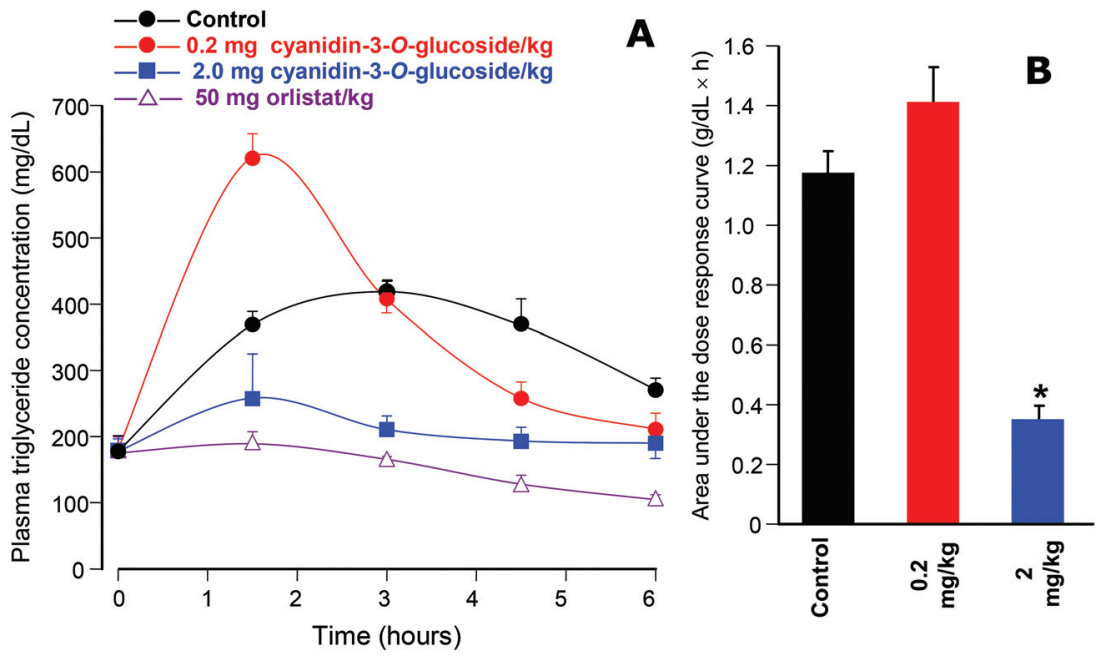

Fig. 11 (A) Plasma triglyceride concentration profiles after intragastric olive oil loads in mice: the effect of cyanidin-3-O-glucoside. The oral administration of olive oil $\left(5 \mathrm{~mL} \mathrm{~kg}{ }^{-1}\right)$ was done immediately after the I administration of cyanidin-3-O-glucoside or orlistat. The doses are given on the graphs. Plasma triglycerides were measured as described in Materials and methods. Each value represents the mean \pm mean standard error of 3 mice. (B) Areas under the curves obtained after the various treatments with of $M$. jaboticaba extract illustrated by panel (A) subtracted from the area under the curve obtained after orlistat administration. Asterisks indicate statistical significance relative to the control curve $(p \leq 0.05)$.

similar to that found with the lowest jabuticaba peel extract dose. After the peak at $1.5 \mathrm{~h}$, however, there was a rapid decline with a tendency of remaining under the control curve during the subsequent 2 hours. The $2.0 \mathrm{mg} \mathrm{kg}^{-1}$ dose, on the other hand, caused a clear diminution in the response. When analyzed in terms of the normalized area under the curves, as it was done with the response to the extract, a clear inhibition of triglyceride absorption by the $2 \mathrm{mg} \mathrm{kg}^{-1}$ dose is apparent (Fig. 11B). With the $0.2 \mathrm{mg} \mathrm{kg}^{-1}$ dose, however, a stimulatory effect seems to predominate even though statistical significance is lacking.

\section{Effects on plasma triglycerides after oleic acid administration}

The effects of cyanidin-3-O-glucoside on triglyceride absorption shown in Fig. 11, in principle at least, are difficult to reconcile with its relatively weak action on the pancreatic lipase in as much as very low doses were administered. It could be that one or more steps of the overall absorption process that are subsequent to the triglyceride hydrolysis step are inhibited. This could involve free fatty acids. For this reason, our approach to this question was to administrate free oleic acid to mice with subsequent measurement of the triolein equivalents in plasma. Table 2 shows the results obtained. Data were expressed as the difference between the basal levels and the levels found at 90 minutes after the administration of oleic acid alone, glycerol alone and oleic acid + glycerol, with or without previous administration of the peel extract or cyanidin-3-O-glucoside. The assay of blood triglycerides that was used in the present work actually measures the glycerol moiety of these molecules. When glycerol was administered alone, however, the assay system displayed a relatively small increase (1.32-fold the basal value), which corresponds to $13 \%$ of the increment that was found in the experiments where glycerol and oleic acid were administered simultaneously (3.5-fold the

Table 2 Increments in plasma triolein equivalents per $100 \mathrm{~mL}$ due to oleic acid, glycerol and oleic acid + glycerol oral loads in mice. The basal concentration of triglycerides in this experimental series was $167.9 \pm 7.7 \mathrm{mg}$ triolein equivalents per $\mathrm{dL}(n=23)$. The asterisks $(*)$ indicate significant difference (Student-Newman-Keuls test) with respect to the experiment group to which only oleic acid plus glycerol were administered. The symbol $\S$ indicates statistical significance of each increment according to the paired $t$-test. The experimental details are described in the Materials and methods section

Intragastric administrations

\begin{tabular}{llll}
\hline $\begin{array}{l}\text { Jabuticaba peel extract } \\
\left(\mathrm{mg} \mathrm{kg}^{-1}\right)\end{array}$ & $\begin{array}{l}\text { Cyanidin-3-O-glucoside } \\
\left(\mathrm{mg} \mathrm{kg}^{-1}\right)\end{array}$ & Substrates & $\begin{array}{l}\text { Increment in plasma } \\
\text { triolein equivalents } \\
\text { after } 90 \mathrm{minutes}\left(\mathrm{mg} \mathrm{dL}^{-1}\right)\end{array}$ \\
\hline- & - & Oleic acid $(180 \mu \mathrm{L})+$ glycerol $(20 \mu \mathrm{L})$ & $424.3 \pm 28.8^{\S}(n=4)$ \\
5.0 & - & Oleic acid $(180 \mu \mathrm{L})+$ glycerol $(20 \mu \mathrm{L})$ & $53.0 \pm 27.0^{*}(n=4)$ \\
25.0 & - & Oleic acid $(180 \mu \mathrm{L})+$ glycerol $(20 \mu \mathrm{L})$ & $66.8 \pm 22.1^{*}(n=3)$ \\
- & 0.2 & Oleic acid $(180 \mu \mathrm{L})+$ glycerol $(20 \mu \mathrm{L})$ & $74.3 \pm 50.0^{*}(n=3)$ \\
- & 2.0 & Oleic acid $(180 \mu \mathrm{L})+$ glycerol $(20 \mu \mathrm{L})$ & $43.0 \pm 38.1^{*}(n=3)$ \\
- & - & Oleic acid $(180 \mu \mathrm{L})$ & $8.3 \pm 2.3^{*}(n=3)$ \\
- & - & Glycerol $(20 \mu \mathrm{L})$ & $54.0 \pm 10.8^{*} \S(n=3)$
\end{tabular}


basal value). When oleic acid was given alone, no increase in the concentration of triacylglycerols in blood was detected, presumably because one of the substrates (glycerol) needed for synthesizing triglycerides was limiting. On the other hand, in all mice that had received either peel extract or cyanidin-3-Oglucoside previous to the glycerol + oleic acid administration, the triglyceride assay system detected only small increments. Actually, none of these increments was statistically different from its corresponding basal value, as revealed by the paired $t$-test. In statistical terms, thus, the effects of the extract and of cyanidin-3-O-glucoside cannot be distinguished from each other. It is worth mentioning that the peel extract doses of 5 and $25 \mathrm{mg} \mathrm{kg}^{-1}$ contained approximately 0.062 and $0.31 \mathrm{mg}$ $\mathrm{kg}^{-1}$ cyanidin-3-O-glucoside.

\section{Discussion}

Composition of the jabuticaba peel extract and general aspects

We have determined the phenolic profile of the extract used in the present work instead of relying on literature data taking into account that preparations of the kind may vary substantially in their composition due to several factors. Regarding the cyanidin-3-O-glucoside content, about $12.34 \mathrm{mg} \mathrm{g}^{-1}$ was found in the extract. This value is less than that reported previously for a similar peel extract $\left( \pm 39.7 \mathrm{mg} \mathrm{g}^{-1}\right.$ extract $),{ }^{5}$ but higher than that one determined in jabuticaba pomace $( \pm 2 \mu \mathrm{g}$ $\mathrm{g}^{-1}$ extract). ${ }^{13}$ The variation in the content of anthocyanin extracted from plant material can be a consequence of several factors, ranging from the conditions of growth/maturation of the plant, preparation of the sample, to the methods of extraction of these compounds from the plant tissue. ${ }^{5}$ Therefore, it is important to note that the fruit ripening points in both studies have not been determined, and distinct drying methods were used (forced-air drying oven/freeze drying), as well as different extraction methods.
Regarding the aims of the present work, two main interconnected questions were formulated in the Introduction: (a) do jabuticaba peel extracts affect starch and triacylglyceride absorption? (b) if yes, what is the contribution of the important component cyanidin-3-O-glucoside? The answer to the first question is positive in that the peel extract clearly inhibited both starch and triglyceride absorption, but the latter effect was considerably stronger than the former. An answer to the second question was equally found: cyanidin-3-O-glucoside only minimally contributes to starch absorption inhibition by the extract; it might eventually affect starch absorption at doses that are well above those contained in the active extract doses. The compound contributes in a decisive manner, however, to the inhibitory effect of the extract on triglyceride absorption, even though this contribution seems to occur predominantly via a mechanism that does not depend on the pancreatic lipase inhibition. Details and implications of each action will be discussed separately in the following items. The scheme in Fig. 12 illustrates the main points of our interpretations and propositions.

\section{Alpha-amylase activity and starch absorption}

Inhibition of starch absorption by jabuticaba extracts and anthocyanins in general has been claimed to represent a possible beneficial action of either the pure compounds or extracts prepared in various ways. ${ }^{6,21}$ With respect to peel extracts, however, it will be impossible to obtain specific inhibition of starch absorption because inhibition of triglyceride absorption occurs at much lower doses. As shown by our experiments, $5 \mathrm{mg} \mathrm{kg}^{-1}$ of the peel extract inhibited triglyceride absorption to an extent that was similar to the inhibition of starch absorption caused by a $500 \mathrm{mg} \mathrm{kg}{ }^{-1}$ dose. The difference comprises, thus, two orders of magnitude. Our in vivo experiments are also not in agreement with previous extrapolations based on enzyme measurements which indicate that cyanidin-3-O-glucoside could be useful as an inhibitor of starch absorption. ${ }^{21,22}$

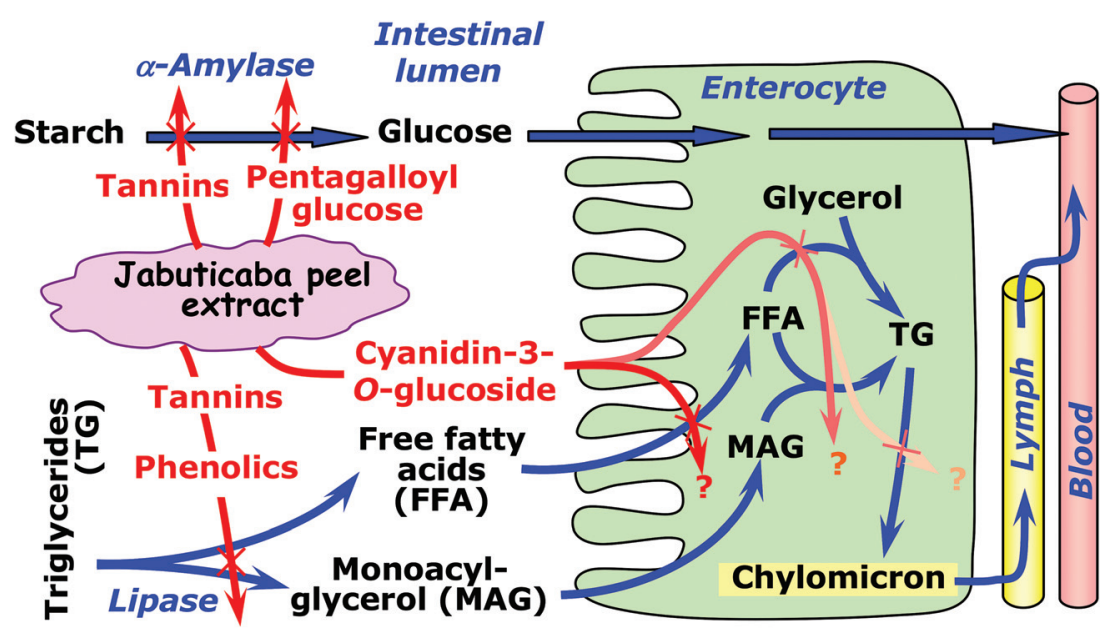

Fig. 12 Possible mechanisms of action and compounds in the jabuticba peel extract involved in the inhibition of starch and triglyceride absorption. 
The reason might be that the action of cyanidin-3-O-glucoside as an inhibitor of $\alpha$-amylase is not strong enough. In this particular respect our results are similar to those reported earlier. In one study, for example, $\mathrm{IC}_{50}$ values of 0.393 and $0.450 \mathrm{mM}$ for the pancreatic and the salivary enzymes, respectively, were found. ${ }^{21}$ Another study reported a $\mathrm{IC}_{50}$ of $0.3 \mathrm{mM}$ for the pancreatic $\alpha$-amylase and a $\mathrm{IC}_{50}>3 \mathrm{mM}$ for the $\alpha$-glucosidase. ${ }^{22}$ These numbers make one to expect that doses of at least $250 \mathrm{mg} \mathrm{kg} \mathrm{kg}^{-1}$ of the compound are necessary for inhibiting starch absorption in vivo. Such a dose is not realistic in terms of the jabuticaba extract and even in pure form. It should also be recalled that when mice were treated in our experiments with realistic doses of cyanidin-3-O-glucoside (10 and $20 \mathrm{mg}$ $\mathrm{kg}^{-1}$ ), no inhibition of starch absorption was found. All these observations indicate the participation of other substances. The extract used in this work contains $28.5 \mathrm{mg} \mathrm{g}^{-1}$ non-anthocyanin polyphenolics. The $\mathrm{IC}_{50}$ for the extract as inhibitor of the $\alpha$-amylase is equal to $1.963 \mathrm{mg} \mathrm{mL}^{-1}$, what corresponds to a total non-anthocyanin polyphenol concentration in the assay system of $69.93 \mu \mathrm{M}$ (summing up individually all compounds and using their molecular weights). If the polyphenolics are the main inhibitors, a reasonable hypothesis, the $\mathrm{IC}_{50}$ values of the most important ones may be significantly smaller than $100 \mu \mathrm{M} .^{23,24}$ For example, one of the components of the jabuticaba extract is pentagalloyl glucose for which we found, in previous work, ${ }^{23}$ inhibition constants of $K_{\mathrm{i} 1}=78.5(\mathrm{EI})$ and $K_{\mathrm{i} 2}=$ $36.4 \mu \mathrm{M}$ (ESI). However, there are other compounds that might be contributing. Tannins, for example, are present in the jabuticaba fruit in relatively large proportions, and are also well known inhibitors of $\alpha$-amylases. ${ }^{16,25}$

Kinetic analysis of the results that were obtained in this work revealed non-competitive inhibition and cumulative binding of inhibitors leading to the formation of the EI, ESI and $\mathrm{EI}_{2}$ complexes or even of higher orders (parabolic inhibition). Eqn (2) that describes this mechanism is the same that gave the best fit to the experimental data obtained with pentagalloyl glucose. ${ }^{23}$ Equations of this kind are useful for predicting the inhibition degree at any combination of substrate and inhibitor concentrations. The heterogeneity of the preparation that was used does not invalidate eqn (2), provided that the proportions between the concentrations of the active compounds are not modified, a condition that holds for extracts with constant composition. ${ }^{26}$ The inhibition constants resulting from the fitting procedure are complex functions of several individual dissociation constants, but still a measure of the strength of the preparation that was used in terms of its mass.

\section{Lipase activity and fat absorption}

Inhibition of the pancreatic lipase by the jabuticaba peel extract is of the parabolic type, at least with $p$-nitrophenyl-palmitate as the substrate, meaning that it can accelerate as the concentration is increased. Double binding by forming binary $\left(\mathrm{ESI}_{2}\right)$ or higher order enzyme-substrate-inhibitor complexes seems to be the cause of the former phenomenon, as indicated by the kinetic analysis. As already mentioned, the inhibitory power of the extract on the pancreatic lipase was 13.6-fold stronger than that on the pancreatic $\alpha$-amylase. The participation of cyanidin-3-O-glucoside, however, is not very pronounced. But, the extract contains several compounds that may act as inhibitors, including several phenolics (see Table 1) and tannins. ${ }^{16,25,27}$ Nonetheless, the potency of the extract used in this work, which revealed an $\mathrm{IC}_{50}$ of $143.9 \mu \mathrm{g} \mathrm{mL} \mathrm{m}^{-1}$, is not exceptional when compared to other preparations from natural products. In a recent survey on formulations from natural products with lipase inhibitor activities, 5 preparations out of 13 are listed as having IC $_{50}$ values smaller than $143.9 \mu \mathrm{g}$ $\mathrm{mL}^{-1} \cdot{ }^{28}$ Based on the available experimental evidence, preparations with $\mathrm{IC}_{50}$ values around $150 \mu \mathrm{g} \mathrm{mL}^{-1}$ would require doses above $100 \mathrm{mg} \mathrm{kg}^{-1}$ in mice to produce significant inhibition of triglyceride absorption. A preparation from the pinhão coat (Araucaria angustifolia), rich in tannins, for example, has an $\mathrm{IC}_{50}$ for the pancreatic lipase inhibition equal to $240 \mu \mathrm{g} \mathrm{mL}^{-1}$ and the dose causing $50 \%$ inhibition of triglyceride absorption is $258.9 \mathrm{mg} \mathrm{kg}{ }^{-1} \cdot{ }^{17}$ The jabuticaba peel extract, however, inhibited triglyceride absorption at much lower doses. Rigoroulsy, inhibition began with the $1 \mathrm{mg} \mathrm{kg}^{-1}$ dose and reached $65 \%$ with the $5 \mathrm{mg} \mathrm{kg}^{-1}$ dose. Taken together, all these characteristics strongly suggest the existence of at least one additional mechanism involved in the modifications in triglyceride absorption caused by the jabuticaba peel extract. This interpretation is reinforced by the effect of purified cyanidin-3-O-glucoside, which is a weak inhibitor of the lipase, but a strong inhibitor of triglyceride absorption at a dose that is consistent with its concentration in the peel extract.

The existence of an alternative and concomitantly operating mechanism is corroborated by the experiments in which free oleate was administered to mice. It is since long known that a free fatty acid load does not promote significant increases in the concentration of nonesterified fatty acids in blood, so that alternative procedures based on the endogenous release of free fatty acids are utilized for evaluating free fatty acid tolerance. ${ }^{29}$ Changes in blood triglycerides, on the other hand, have been since long regarded as a way of estimating free fatty acids absorption. ${ }^{30,31}$ The assay procedure used in the present study does not exclude interference by free glycerol, which can be neglected in triacylglycerol tolerance tests because in this case the administered triglycerides are anyway the only source of the glycerol moiety. The data obtained in the experiments of this work in which free oleic acid was administered can also be regarded technically as an oleic acid-dependent absorption of glycerol. However, based on the well-established notion that the glycerol 3-phosphate pathway of triglycerides synthesis is fully operative in enterocytes (in addition to the monoacyl glycerol pathway) ${ }^{32}$ and the results of our control experiments, it seems reasonable to assume that the transport of free glycerol alone into plasma is severely limited and that it enters blood mainly in the form of triacylglycerols after being co-absorbed with oleic acid. In this respect it can be considered quite significant that both cyanidin-3-O-glucoside and the peel extract strongly inhibited the glycerol dependent co-absorption of 
oleic acid, a phenomenon that occurred with doses of cyanidin-3-O-glucoside that are consistent with its concentration in the extract. The bulk of the observations strongly suggest that the inhibitory effect of low doses of the jabuticaba extract may occur with a significant if not predominating contribution of cyanidin-3-O-glucoside.

Inhibition of triglyceride absorption by mechanisms that are concomitant or even independent of the inhibition of lipases have already been suggested by several studies. Even for orlistat, the classical inhibitor of triglyceride absorption, inhibition of fatty acyl synthase is now accepted as an additional action that superimposes on the lipase inhibitory activity. $^{33}$ The mechanism by which cyanidin-3-O-glucoside acts cannot be deduced from the results of this work. The overall process of fatty acid absorption and subsequent release as triglycerides is actually fairly complex and consists in various steps involving several enzymes and proteic factors. ${ }^{34-36}$ Full clarification of the action of cyanidin-3-O-glucoside or that of other compounds in the jabuticaba peel extract will certainly require exhaustive and specific experimentation. Hypotheses, however, can be formulated. Cyanidin-3-Oglucoside could be acting on the transport of free fatty acids across the enterocyte membrane or it could be inhibiting one or more post-absorption metabolic steps in the process of triglyceride synthesis as illustrated by Fig. 12. Inhibition of glycerol transport from the lumen into the enterocyte is much less likely it one takes into account that cyanidin-3-O-glucoside also inhibited the absorption of triglycerides, a process in which monoacyl-glycerol is the main glycerol source. It is presently accepted that free fatty acids, in spite of their lipophilic nature, have their movements across the cell membrane and across the cellular compartments greatly facilitated when bound to specific proteins. Up to now three classes of fatty acid transport proteins have been described: the fatty acid binding protein (FABP), the fatty acid translocase (FAT, also known as scavenger receptor CD36), and the family of fatty acid transport proteins (FATP1-6). ${ }^{36-38}$ It has also been suggested that some of these proteins might be arranged in a complex within the cell membrane, for example the FAT plus FATP in addition to the very-long chain acyl CoA synthase, in order to promote a more effective transportation of free fatty acids through the cell membrane coupled to their transformation along the cell space in direction to the sites where incorporation into supramolecular structures occurs. ${ }^{37,38}$ Inhibitors of these transport proteins have already been identified, most of them of plant origin. Lipofermat, for example, inhibits free fatty acid transport in several cell types, including intestinal epithelial cells. $^{36,39}$ Consistently, it has been shown that this compound also inhibits, in a dose-dependent manner, the incorporation of orally administered $\left[{ }^{13} \mathrm{C}\right]$ oleate into plasma lipids in mice. $^{39}$ Lipofermat and cyanidin-3-O-glucose are different molecules having in common, however, aromatic rings in their structures, which should facilitate their interactions with the lipophilic environment that fatty acids require for transportation, diffusion and transformation. The results obtained in this study allow to suggest, thus, that cyanidin-3-
$O$-glucose might be an inhibitor of free fatty acid transport. Alternatively, it is equally possible that cyanidin-3-O-glucose acts by inhibiting one or more steps in the metabolic transformations that lead to the transformation of free fatty acids into triglycerides via both the monoacylglycerol or glycerol 3-phoshate pathways, ${ }^{32}$ especially if one considers that these transformations occur in a complex lipidic environment. Only specific experimentation will allow to decide among these two possibilities. Experimentation must also take into account the observation of a higher plasma triglyceride concentration at 90 minutes following the olive oil load when the lowest extract and cyanidin-3-O-glucoside doses were administered (Fig. 10 (A) and 11(A)). The curves decline strongly afterwards, but they may be revealing a fast-stimulatory action that superimposes on the inhibitory action that predominates later in time and is the only effect that can be seen at higher doses. It should be stressed that this phenomenon was observed with both pure cyanidin-3-O-glucose and the peel extract. This observation actually denotes a highly complex action mechanism for cyanidin-3-O-glucoside and possibly other components of the jabuticaba peel extract, a characteristic that will certainly stimulate future work on the subject.

\section{Conclusion}

It can be concluded that the jabuticaba peel extract presents many favourable perspectives as an inhibitor of fat absorption and that cyanidin-3-O-glucoside, one of its main constituents, seems to play a decisive role. Application of the peel extract or even pure cyanidin-3-O-glucoside as weight reducing pharmacological agents and diets for treating obesity seems to be a real possibility. A fundamentally important characteristic of the jabuticaba peel extract is the low doses that are required to reduce fat absorption. This requirement extends also to the component cyanidin-3-O-glucoside. However, in practical terms, the preparation of an effective jabuticaba peel extract is much easier and cheaper in contrast to cyanidin-3-O-glucoside, whose isolation in pure form seems to be quite expensive, at least at the present stage. Moreover, as it has been investigated by our team, jabuticaba peel extracts also have potential for being used as natural colorants in the food industry. ${ }^{40}$ Thus, the combination of these functionalities, enhances the interest in its exploration as a source of high added-value ingredient for the production of functional foods. Furthermore, the jabuticaba skins are usually discarded during industrial processing of the fruit, a fact that generates abundant and cheap feedstock for semi-purified pharmaceutical formulations and food additives. In such a context further mechanistic and perhaps clinical studies are certainly highly desirable.

\section{Statement of contributions}

Adelar Bracht: conceptualization, methodology, validation, formal analysis, data curation, writing, review and editing, 
funding acquisition, visualization; Anacharis Babeto de SáNakanishi: conceptualization, methodology, validation, formal analysis, data curation, writing, review and editing; Bianca R. Albuquerque: investigation; Isabel C. F. R. Ferreira: methodology, resources, funding acquisition; Jurandir Fernando Comar: methodology, validation; Lillian Barros: methodology, formal analysis, resources, data curation, funding acquisition, writing, review and editing; Lívia Bracht: methodology, validation; Maria Inês Dias: investigation; Pamela Alves Castilho: investigation, original draft preparation; Rosane Marina Peralta: conceptualization, methodology, resources, review and editing, funding; Tamires Barlatti Barlati Vieira da Silva: investigation.

\section{Conflicts of interest}

There are no conflicts to declare.

\section{Acknowledgements}

This work was financially supported by grants from the Conselho Nacional de Desenvolvimento Científico e Tecnológico (CNPq-304090/2016-6) and Coordenação do Aperfeiçoamento de Pessoal do Ensino Superior (CAPES). The authors are grateful to the Foundation for Science and Technology (FCT, Portugal) for financial support through national funds FCT/MCTES to CIMO (UIDB/00690/2020) and through the institutional scientific employment program-contract for L. Barros contract. This work was also funded by the European Regional Development Fund (ERDF) through the Regional Operational Program North 2020, within the scope of Project Mobilizador Norte-01-0247-FEDER-024479: ValorNatural®.

\section{Notes and references}

1 A. A. Reynertson, H. Yang, B. Jiang, M. J. Basile and E. J. Kennelly, Quantitative analysis of antiradical phenolic constituents from fourteen edible Myrtaceae fruits, Food Chem., 2008, 109, 883-890, DOI: 10.1016/j. foodchem.2008.01.021.

2 M. R. Alezandro, P. Dubé, Y. Desjardins, F. M. Lajolo and M. I. Genovese, Comparative study of chemical and phenolic compositions of two species of jaboticaba: Myrciaria jaboticaba (Vell.) Berg and Myrciaria cauliflora (Mart.) O. Berg, Food Res. Int., 2013, 54, 468-477, DOI: 10.1016/J. foodres.2013.07.018.

3 K. O. O. Inada, A. A. Oliveira, T. B. Revorêdo, A. B. N. Martins, E. C. Q. Lacerda, A. S. Freire, B. F. Braz, R. E. Santelli, A. G. Torres, D. Perrone and M. C. Monteiro, Screening of the chemical composition and occurring antioxidants in jabuticaba (Myrciaria jaboticaba) and jussara (Euterpe edulis) fruits and their fractions, J. Funct. Foods, 2015, 17, 422-433, DOI: 10.1016/J.JFF.2015.06.002.
4 A. J. B. Lima, A. D. Corrêa, A. P. C. Alves, C. M. P. Abreu and A. M. Dantas-Barros, Caracterização química do fruto jabuticaba (Myrciaria cauliflora Berg) e de suas frações, Arch. Latinoam. Nutr., 2008, 58, 416-421. Retrieved from http://ve.scielo.org/scielo.php?script=sci_arttext\&pid= S0004-06222008000400015.

5 B. R. Albuquerque, C. Pereira, R. C. Calhelha, M. J. Alves, R. M. V. Abreu, L. Barros, B. P. P. Oliveira and I. C. F. R. Ferreira, Jabuticaba residues (Myrciaria jaboticaba (Vell.) Berg) are rich sources of valuable compounds with bioactive properties, Food Chem., 2020, 125735, DOI: 10.1016/j.foodchem.2019.125735.

6 M. R. Alezandro, D. Granato and M. I. Genovese, Jaboticaba (Myrciaria jaboticaba (Vell.) Berg), a Brazilian grape-like fruit, improves plasma lipid profile in streptozotocinmediated oxidative stress in diabetic rats, Food Res. Int., 2013a, 54, 650-659, DOI: 10.1016/j.foodres.2013.07.041.

7 A. G. Batista, S. A. Lenquiste, C. Moldenhauer, J. T. Godoy, S. M. P. Machado Reis and M. R. Maróstica Júnior, Consumo de casca de jabuticaba (Myrciaria jaboticaba (Vell.) Berg.) melhorou a excreção de triglicerídeos e a peroxidação lipídica hepática de ratos alimentados com dieta hiperlipídica, Rev. Nutr., 2013, 26, 571-581, DOI: 10.1590/S1415-52732013000500008.

8 S. A. Lenquiste, A. G. Batista, R. S. Marineli, N. R. V. Dragano and M. R. Maróstica, Freeze-dried jaboticaba peel added to high-fat diet increases HDL-cholesterol and improves insulin resistance in obese rats, Food Res. Int. , 2012, 49, 153-160, DOI: 10.1016/j.foodres.2012.07.052.

9 X. Wei, D. Wang, Y. Yang, M. Xia, D. Li, G. Li, Y. Zhu, Y. Xiao and W. Ling, Cyanidin-3-O- $\beta$-glucoside improves obesity and triglyceride metabolism in KK-Ay mice by regulating lipoprotein lipase activity, J. Sci. Food Agric., 2011, 91, 1006-1013, DOI: 10.1002/jsfa.4275.

10 Y. You, X. Yuan, X. Liu, C. Liang, M. Meng, Y. Huang, X. Han, J. Guo, Y. Guo, C. Ren, Q. Zhang, X. Sun, T. Ma, G. Liu, W. Jin, W. Huang and J. Zhan, Cyanidin-3-glucoside increases whole body energy metabolism by upregulating brown adipose tissue mitochondrial function, Mol. Nutr. Food Res., 2017, 61, 1700261, DOI: 10.1002/ mnfr.201700261.

11 Y. You, X. Han, J. Guo, Y. Guo, M. Yin, G. Liu, W. Huang and J. Zhan, Cyanidin-3-glucoside attenuates high-fat and high-fructose diet-induced obesity by promoting the thermogenic capacity of brown adipose tissue, J. Funct. Foods, 2018, 41, 62-71, DOI: 10.1016/j.jff.2017.12.025.

12 R. Sasaki, N. Nishimura, H. Hoshino, Y. Isa, M. Kadowaki, T. Ichi, A. Tanaka, S. Nishiumi, I. Fukuda, H. Ashida, F. Horio and T. Tsuda, Cyanidin- 3-glucoside ameliorates hyperglycemia and insulin sensitivity due to downregulation of retinol binding protein 4 expression in diabetic mice, Biochem. Pharmacol., 2007, 74, 1619-1627, DOI: 10.1016/j.bcp.2007.08.008.

13 P. Morales, L. Barros, M. I. Dias, C. Santos-Buelga, I. C. F. R. Ferreira, E. R. Asquieri and J. D. J. Berrios, Nonfermented and fermented jabuticaba (Myrciaria cauliflora 
Mart.) pomaces as valuable sources of functional ingredients, Food Chem., 2016, 208, 220-227, DOI: 10.1016/j. foodchem.2016.04.011.

14 G. L. Miller, Use of dinitrosalicylic acid reagent for determination of reducing sugar, Anal. Chem., 1959, 31, 426-428, DOI: $10.1021 / \mathrm{ac60147a030.}$

15 S. M. da Silva, E. A. Koehnlein, A. Bracht, R. Castoldi, G. R. de Morais, M. L. Baesso, R. A. Peralta, C. G. M. de Souza, A. B. de Sá-Nakanishi and R. M. Peralta, Inhibition of salivary and pancreatic $\alpha$-amylases by a pinhão coat (Araucaria angustifolia) extract rich in condensed tannin, Food Res. Int., 2014, 56, 1-8, DOI: 10.1016/j. foodres.2013.12.004.

16 C. G. Kato, G. de A. Gonçalves, R. A. Peralta, F. A. V. Seixas, A. B. Sá-Nakanishi, L. Bracht, J. F. Comar, A. Bracht and R. M. Peralta, Inhibition of $\alpha$-amylases by condensed and hydrolysable tannins: focus on kinetics and hypoglycemic actions, Enzyme Res., 2017, 5724902, DOI: 10.1155/2017/ 5724902 .

17 R. F. Oliveira, G. A. Gonçalves, F. D. Inácio, E. A. Koehnlein, C. G. M. de Souza, A. Bracht and R. M. Peralta, Inhibition of pancreatic lipase and triacylglycerol intestinal absorption by a Pinhão coat (Araucaria angustifolia) extract rich in condensed tannin, Nutrients, 2015, 7, 5601-5614, DOI: 10.3390/nu7075242.

18 C. Luley, G. Ronquist, W. Reuter, V. Paal, H. D. Gottschling, S. Westphal, G. L. King, S. J. L. Bakker, R. J. Heine and A. Hattemer, Point-of-care testing of triglycerides: evaluation of the accutrend triglycerides system, Clin. Chem., 2000, 46, 287-291, DOI: 10.1093/clinchem/46.2.287.

19 H. Akaike, A new look at the statistical model identification, IEEE Trans. Autom. Control, 1974, 19, 716-723, DOI: 10.1109/TAC.1974.1100705.

20 T. Y. Wang, M. Liu, P. Portincasa and D. Q. H. Wang, New insights into the molecular mechanism of intestinal fatty acid absorption, Eur. J. Clin. Invest., 2013, 43, 1203-1133, DOI: $10.1111 /$ eci.12161.

21 S. Wiese, S. Gärtner, H. M. Rawel, P. Winterhalter and S. E. Kulling, Protein interactions with cyanidin-3-glucoside and its influence on $\alpha$-amylase activity, J. Sci. Food Agric., 2009, 89, 33-40, DOI: 10.1002/jsfa.3407.

22 S. Akkarachiyasit, P. Charoenlertkul, S. Yibchok-anun and S. Adisakwattana, Inhibitory activities of cyanidin and its glycosides and synergistic effect with acarbose against intestinal $\alpha$-glucosidase and pancreatic $\alpha$-amylase, Int. J. Mol. Sci., 2010, 11, 3387-3396, DOI: 10.3390/ ijms11093387.

23 C. G. Kato-Schwartz, F. G. A. Goncalves, A. A. Soares, T. F. Vieira, T. Brugnari, A. Bracht and R. M. Peralta, Inhibition of alpha-amylases by pentagalloyl glucose: kinetics, molecular dynamics and consequences for starch absorption, J. Funct. Foods, 2018, 44, 265-273, DOI: 10.1016/j.jff.2018.03.025.

24 V. Desseaux, P. Stocker, P. Brouant and E. H. Ajandouz, The mechanisms of alpha-amylase inhibition by flavan-3ols and the possible impacts of drinking green tea on starch digestion, J. Food Sci., 2018, 83, 2858-2865, DOI: 10.1111/1750-3841.14353.

25 G. A. C. Fortes, S. S. Naves, P. H. Ferri and S. C. Santos, Evaluation of chemical changes during Myrciaria cauliflora (Jabuticaba Fruit) Fermentation by $1 \mathrm{H}$ NMR spectroscopy and chemometric analyses, J. Braz. Chem. Soc., 2012, 23, 1815-1822, DOI: 10.1590/S010350532012005000050.

26 T. C. Chou and P. Talalay, A simple generalized equation for the analysis of multiple inhibitions of MichaelisMenten kinetic systems, J. Biol. Chem., 1977, 252, 64386442 http://intl.jbc.org/cgi/content/abstract/252/18/6438.

27 E. N. Moreno-Córdova, A. A. Arvizu-Flores, E. M. Valenzuela-Soto, K. D. García-Orozco, A. WalMedrano, E. Alvarez-Parrilla, J. F. Ayala-Zavala, J. A. Domínguez-Avila and G. A. González-Aguilar, Gallotannins are uncompetitive inhibitors of pancreatic lipase activity, Biophys. Chem., 2020, 264, 106409, DOI: 10.1016/j.bpc.2020.106409.

28 T. T. Liu, X. T. Liu, Q. X. Chen and Y. Shi, Lipase inhibitors for obesity: a review, Biomed. Pharmacother., 2020, 128, 110314, DOI: 10.1016/j.biopha.2020.110314.

29 S. Westphal, G. H. Gekeler, J. Dierkes, H. Wieland and C. Luley, A free fatty acid tolerance test identifies patients with coronary artery disease among individuals with a low conventional risk profile, Heart Vessels, 2002, 16, 79-85, DOI: $10.1007 / \mathrm{s} 003800200000$.

$30 \mathrm{H}$. C. Tidwell, Mechanism of fat absorption as evidenced by chylomicrographic studies, J. Biol. Chem., 1950, 182, 405-414 http://www.jbc.org/content/182/1/405.citation.

31 W. J. Simmonds, T. G. Redgrave and R. L. S. Willix, Absorption of oleic and palmitic acids from emulsions and micellar solutions, J. Clin. Invest., 1968, 47, 1015-1025, DOI: $10.1172 /$ JCI105791.

32 C. L. E. Yen, D. W. Nelson and M. I. Yen, Intestinal triacylglycerol synthesis in fat absorption and systemic energy metabolism, J. Lipid Res., 2015, 56, 489-501, DOI: 10.1194/ jlr.R052902.

33 D. Buckley, G. Duke, T. S. Heuer, M. O'Farrell, A. S. Wagman, W. McCulloch and G. Kemble, Fatty acid synthase - Modern tumor cell biology insights into a classical oncology target, Pharmacol. Ther., 2017, 177, 23-31, DOI: $10.1016 /$ j.pharmtera.2017.02.021.

34 E. Ros, Intestinal absorption of triglyceride and cholesterol. Dietary and pharmacological inhibition to reduce cardiovascular risk, Atherosclerosis, 2000, 151, 357-379, DOI: 10.1016/s0021-9150(00)00456-1.

35 T. Y. Wang, M. Liu, P. Portincasa and D. Q. H. Wang, New insights into the molecular mechanism of intestinal fatty acid absorption, Eur. J. Clin. Invest., 2013, 43, 1203-1223, DOI: $10.1111 /$ eci.12161.

36 K. Schreck and M. F. Melzig, Intestinal saturated long-chain fatty acid, glucose and fructose transporters and their inhibition by natural plant extracts in Cco-2 cells, Molecules, 2018, 23, 2544, DOI: 10.3390/ molecules23102544. 
37 A. Stahl, D. J. Hirsch, R. E. Gimeno, S. Punreddy, P. Ge, N. Watson, S. Patel, M. Kotler, A. Raimondi, L. A. Tartaglia and H. F. Lodish, Identification of the major intestinal fatty acid transport protein, Mol. Cell, 1999, 4, 299-308, DOI: 10.1016/s1097-2765(00)80332-9.

38 A. Stahl, R. E. Gimeno, L. A. Tartaglia and H. F. Lodish, Fatty acid transport proteins: A current view of a growing family, Trends Endocrinol. Metab., 2001, 12, 266-273, DOI: 10.1016/s1043-2760(01)00427-1.

39 C. Ahowesso, P. N. Black, N. Saini, D. Montefusco, J. Chekal, C. Malosh, C. W. Lindsley, S. R. Stauffer and
C. C. Di Russo, Chemical inhibition of fatty acid absorption and cellular uptake limits lipotoxic cell death, Biochem. Pharmacol., 2015, 98, 167-181, DOI: 10.1016/j. bcp.2015.09.004.

40 B. R. Albuquerque, J. Pinela, L. Barros, N. B. P. P. Oliveira and I. C. F. R. Ferreira, Anthocyanin-rich extract of jabuticaba epicarp as a natural colorant: optimization of heat- and ultrassoundassisted extraction and applications in a bakery product, Food Chem., 2020, 316, 126364, DOI: 10.1016/j.foodchem. 2020.126364 . 